Published as: Neutens, T., Farber, S., Delafontaine, M., Boussauw, K. (2013). Spatial variation in the potential for social interaction: A case study in Flanders (Belgium). Computers, Environment and Urban Systems, vol. 41: 318-331.

\title{
Spatial Variation in the Potential for Social Interaction: A Case Study in Flanders (Belgium)
}

\begin{abstract}
.
Empirical evidence is mounting that good urban design fosters the formation of social fabric. Existing evidence is however limited in at least two respects. First, empirical studies have focused largely on social interactions taking place within the residential neighborhood, while leaving social encounters near the workplace unconsidered. Second, while various studies have examined the impact of the built environment on realized social behavior, there is as yet no empirical research on the potential for having social contact. A deeper understanding of the geography of social interaction potential is nonetheless important, for it is individuals' social opportunities rather than their preferences and actual choices that are most directly amenable to policy intervention. This paper seeks to address both issues in an empirical case study in Flanders and Brussels (Belgium). An exploratory spatial analysis is conducted to uncover spatial trends in the potential for social interaction in order to better understand the role of urban spatial structure in the production of social interaction potential.
\end{abstract}

Keywords. social interaction; urban form; time geography 


\section{Introduction}

It is a truism that social cohesion and community interaction lie at the heart of society by fostering reciprocity and trust among citizens (Putnam, 2000). Communities with higher levels of supportive inter-personal interactions are likely to inspire educational achievement, civic engagement, economic development, responsive democracy, innovation and safety. At the individual level, being socially involved is conducive to health and well-being as well as the ability to find higher paying jobs.

The need to build communities that promote social and health welfare has long been a central concern among planning practitioners and scholars (Jacobs, 1961). Empirical evidence is mounting that good urban design encourages the formation of social fabric. In particular, lowdensity, automobile-oriented suburban development is said to be inimical to impromptu neighborly interactions, while high-density, pedestrian-friendly neighborhoods with mixed landuses are credited with increased levels of neighborliness and social vibrancy. Freeman (2001), for instance, suggests a powerful negative relationship between the level of car use and the number of social ties in a neighborhood. Leyden (2003) and Lund (2003), for their part, found that people living in walkable neighborhoods tend to experience enhanced levels of social interaction relative to those living in automobile-oriented neighborhoods.

The alleged relationships between urban design and social interaction are often gladly employed by New Urbanists, New Town advocates and other urban reformists to buttress criticism of urban sprawl in favor of promoting compact urban areas (Sander, 2002; Talen, 2002). Meanwhile, however, a number of scholars have also brought opposing evidence to the fore suggesting that urban sprawl in itself does not necessarily undermine social contact. Regressing individuals' social interaction variables on census-tract density, among other variables, Brueckner and Largey (2008) observed that low-density living has a positive, rather than negative, effect on the propensity to engage in social activities. Hence, they assert that the argument of deterred social cohesion should not be incorporated in the panoply of critiques on urban sprawl. Likewise, Nguyen (2010) concluded that "compact living, as characterized by high population density and street accessibility at the county level, is unfavorable to social interaction, faith-based social relationships, and giving and volunteering". 
Studies on either side of the debate, however, have at least two important limitations. First, they focus largely on social contact taking place within the residential neighborhood, while leaving individuals' social encounters near the work location unconsidered. In other words, the implications of urban sprawl and other design alternatives for individuals' commuting behavior across the wider metropolitan region are not accounted for. This is to be deemed a harmful limitation given that lengthy commutes may adversely affect the frequency and duration of being involved in social activities (see Farber \& Paez, 2009; 2011 for a detailed study on this matter). Furthermore, the narrow focus on neighborhood social ties is in sharp contrast with empirical evidence suggesting a tendency toward decreased intra-neighborhood and increased extraneighborhood socializing (Forrest \& Kearns, 2001; Guest \& Wierzbicki, 1999). Second, the existing studies examined the impact of the built environment on such realized social interaction variables as the frequency of socializing with neighbors, membership in hobby-oriented clubs and attending church, but did not assess the potential for having social contact. Gaining insight into social interaction potential is nonetheless important for it is individuals' potential rather than their willingness to partake in social activities that is most directly amenable to policy intervention. This view aligns with the long-standing tradition of time geography in the social sciences which emphasizes the importance of constraints on (joint) activity participation (Hägerstrand, 1970; Lenntorp, 1978). Also, considering potential instead of observed social behavior enables to circumvent the issue of self-selection (i.e. social people tend to prefer walkable neighborhoods, rather than walkable neighborhoods encouraging sociability).

In an effort to solidify our understanding of both aspects in the ongoing discourse regarding the link between urban form and social interaction, we have developed a method for measuring the social interaction potential at the scale of metropolitan regions. The method is described in detail in Farber, et al. (2012), but its fundamentals will be recapitulated in the next section. The method makes allowance for commuter flows and time budgets as well as for the land-use and transport system within a region. It has previously been tested with experimental data of synthetically constructed cities with differing land-use configurations and daily commute-flow characteristics. This paper presents an empirical application of the metrics proposed in Farber et al. (2012). It uses actual data from Flanders (Belgium) and Brussels to perform an exploratory spatial analysis of the geography of social interaction potential in this region. The aim of this comprehensive exercise is to uncover spatial trends in the potential for social interaction in order to better 
understand the role of urban spatial structure in the production of social interaction potential. It should be emphasized, however, that this empirical study will look only at the space-time opportunities for having social (face-to-face) contact. The implications of having more such opportunities for social capital (Bordieu, 1986; Coleman, 1988) remain implicit and are merely hypothesized. The reader should thus appreciate that the potential for having social contact is an important, yet not the only prerequisite for accruing social capital. Various other structural and cognitive preconditions, including the quality of social resources (see Rostila, 2011), need to be considered to fully grasp the notion of social capital.

The remainder of this paper is organized in four sections. The next section describes the fundamentals of the method introduced earlier in Farber et al. (2012). Section 3 presents the study area, data, assumptions and computational aspects. Results are presented and discussed in section 4. Finally, the paper concludes with a brief outline of the major findings as well as the avenues for future work.

\section{Method}

\subsection{Conceptual approach}

Central to our approach (see also Farber, et al., 2011) is the derivation of the potential for social interaction from the intersection of space-time prisms (Figure 1). A space-time prism is a key concept of time geography and gathers all space-time points that are physically accessible to an individual given one or more space-time anchors, the maximum velocity of physical movement and the minimum time required for some activity (Hägerstrand, 1970). Space-time anchors represent key locations in an individual's life, such as home and work, where activities with a high degree of space-time fixity are undertaken - that is, activities that are relatively difficult to re-schedule or re-locate in the short run. Space-time anchors condition physical accessibility by dictating where and when discretionary travel and activities must start and end (Cullen \& Godson, 1975; Kwan \& Hong, 1998; Miller, 2005a).

\section{[insert Figure 1 here]}

In recent years, several authors have relied on prism intersections as a way to model the potential for social interaction. Recent accomplishments in this field include the implementation of 
toolkits for querying and representing the opportunities for joint activity participation and intrahousehold interaction (Kang \& Scott, 2008; Kwan \& Lee, 2011; Neutens, et al., 2010b; Yu \& Shaw, 2008), the theoretical formulation of necessary conditions for physical and virtual interaction (Miller, 2005b) and the development of an analytical framework for measuring joint accessibility (Fang, et al., 2011; Neutens, et al., 2010a; Neutens, et al., 2008).

In line with these studies (ibid.), we will express the potential for social interaction in terms of the amount of time available for interaction with others within a particular time budget. As commuting constitutes the primary nexus of daily spatial mobility (Salze, et al., 2011), the subsequent theoretical and empirical development will concentrate on the interaction possibilities within a single time budget between work and home. In other words, individual prisms will be anchored at the home and work location as depicted in Figure 1. The model can be extended to other parts of the day and multiple time budgets in future research, with the appropriate modifications. As journey-to-work travel data for an entire metropolitan region is typically not available at the individual level, we will adopt a zonal approach and consider commuting flows from one zone to another. Hence, we will translate the microscopic rendezvous scenario between two individuals, as depicted in Figure 1, to a general situation where an individual with a particular commuting pattern may socialize with all other commuters in a given metropolitan region. This means that we are concerned with the potential intersection of zone-to-zone commuting flows rather than prism intersections of separate individuals living and working at discrete anchor locations. In the next section we will explain more formally how these intersections can be computed.

\subsection{Theoretical framework}

The amount of time available for an individual living in zone $i$ and working in zone $j$ to perform an after-work out-of-home activity in zone $k$ is expressed as:

$T_{i j}^{k}=\left\{\begin{array}{cl}t_{b_{i j}}-\left(t_{j k}+t_{k i}\right) & \text { if } t_{j k}+t_{k i}<t_{b_{i j}} \\ 0 & \text { otherwise }\end{array}\right.$

where $t_{b_{i j}}=t_{h_{i j}}-t_{w_{i j}}$ is the time available for a discretionary activity after leaving work and before arriving home; $t_{j k}$ is the time it takes to travel from work in zone $j$ to zone $k$; $t_{k i}$ is the time it takes to travel from zone $k$ back to home in zone $i ; t_{w_{i j}}$ is the time the individual can 
leave work; and $t_{h_{i j}}$ is the time the individual must arrive back at home. Note that equation (1) ensures that time availability is constrained to non-negative numbers. $T_{i j}^{k}$ can be considered the maximum amount of time an individual can be in zone $k$ given the capability constraint of physical travel through space and the work/home anchor constraints.

Let $T_{i j}^{k_{S}}=t_{w_{i j}}+t_{j k}$ be the start time of the time window of $T_{i j}^{k}$ and let $T_{i j}^{k_{E}}=t_{h_{i j}}-t_{k i}$ be the last moment of time an individual may be in zone $k$ before needing to return home. Likewise, $T_{q r}^{k_{S}}=t_{w_{q r}}+t_{r k}$ and $T_{q r}^{k_{E}}=t_{h_{q r}}-t_{k q}$ denote the start and end times of the time window in zone $k$ for an individual living in zone $q$ and working in zone $r$.

It then follows that the amount of time these two individuals can interact in zone $k$ is:

$T_{i j q r}^{k}=\left\{\begin{array}{cl}\min \left(T_{i j}^{k_{E}}, T_{q r}^{k_{E}}\right)-\max \left(T_{i j}^{k_{S}}, T_{q r}^{k_{S}}\right) & \text { if } \min \left(T_{i j}^{k_{E}}, T_{q r}^{k_{E}}\right)>\max \left(T_{i j}^{k_{S}}, T_{q r}^{k_{S}}\right) \\ 0 & \text { otherwise }\end{array}\right.$.

Again, equation (2) ensures that the time duration for a joint activity is non-negative.

Furthermore, given a finite set $K$ of discrete potential interaction zones, the total potential time available for after-work interaction between these two individuals can simply be expressed as:

$T_{i j q r}=\sum_{k \in K} T_{i j q r}^{k}$

Now suppose there is a metropolitan region with $n$ zones and a working population $R$. Let $|R|=$ $\sum_{i, j} r_{i j}$ where $r_{i j}$ is the number of workers living in zone $i$ and working in zone $j$. Additionally, let $P_{i j}=\frac{r_{i j}}{|R|}$ be the share of workers in the metropolitan region that travel from zone $i$ to zone $j$.

Then,

$M_{c}=\sum_{i} \sum_{j} \sum_{q} \sum_{r}\left(T_{i j q r} P_{i j} P_{q r}\right)$

constitutes a metric of social interaction potential for metropolitan region $c$ dependent on the spatial configuration of land-uses and transport infrastructure, and the realized commuting flows of the region. $M_{c}$ can be interpreted as the aggregate of potential social interaction time between all pairs of commuters in the city, weighted by the likelihood of occurrence of each type of commute. 
The metric $M_{c}$ attains a maximum when travel velocities are infinite, or when all residential, employment, and social activity locations are exactly collocated and no travel is needed in the system. This maximum is given by

$M_{c_{\max }}=K_{c} \sum_{i} \sum_{j} \sum_{q} \sum_{r} P_{i j} P_{q r}\left[\min \left(t_{h_{i j}}, t_{h_{q r}}\right)-\max \left(t_{w_{i j}}, t_{w_{q r}}\right)\right]$

where $K_{C}$ is the number of zones defining metropolitan region $c$.

The metric attains its minimum of 0 when the required time to reach all social activity locations is greater than the allowed after-work time budgets (i.e. $\forall i, j, k: t_{j k}+t_{k i} \geq t_{b}$ ).

In order to make absolute amounts of social interaction opportunity of different regions commensurable, normalization by the number of social interaction zones identified in each region is required. Dividing $M_{c}$ by $K_{c}$ modifies the interpretation of the metric to be the expected amount of social interaction time at any location between any two commuters in the considered urban region.

$M_{c}$ can be decomposed into four meaningful metrics which will be employed to examine the social potential of zones internal to a given metropolitan region These metrics include:

1. $M_{c i}=\sum_{j} \sum_{q} \sum_{r}\left(T_{i j q r} P_{i j} P_{q r}\right)$

2. $M_{c j}=\sum_{i} \sum_{q} \sum_{r}\left(T_{i j q r} P_{i j} P_{q r}\right)$

3. $M_{c i j}=\sum_{q} \sum_{r}\left(T_{i j q r} P_{i j} P_{q r}\right)$

4. $M_{c k}=\sum_{i} \sum_{j} \sum_{q} \sum_{r}\left(T_{i j q r}^{k} P_{i j} P_{q r}\right)$

Notice that $M_{c}=\sum_{i} M_{c i}=\sum_{j} M_{c j}=\sum_{i} \sum_{j} M_{c i j}=\sum_{k} M_{c k}$. The first metric will be used to determine the social potential of living in zone $i$ of urban region $c$. The second for determining the social potential of having a job in zone $j$. The third for determining the social potential associated with a given daily commute from zone $i$ to $j$. And the fourth will be used to determine the amount of potential social interaction demand in zone $k$.

For a more elaborate discussion of the scope and interpretation of the proposed metrics as well as their broader applications, the reader is referred to Farber et al. (2012). 


\subsection{Example}

As an illustration, we will show how $M_{c i j}$ (the metric with the least iterations, see equation (8)) can be calculated in practice using a simple example of a fictitious metropolitan area containing 100 workers and consisting of three zones A, B and C. Commuting flows as well as travel times within and between the zones are presented in Figure 2. For example, zone B attracts 20 workers from zone $\mathrm{A}$ and 25 from zone $\mathrm{C}$, who need to travel 12 and 20 minutes to their work place, respectively. Zone B also employs local workers from within the zone who on average travel 7 minutes to their workplace. It is assumed that the time budgets of all individuals within the metropolitan area equal 90 minutes, starting at 5 PM and ending at 6.30 PM.

[insert Figure 2 here]

The social interaction potential associated with a daily commuting flow from zone A to B can then be calculated as follows:

$$
\begin{aligned}
& M_{C A B}=\sum_{q} \sum_{r}\left(T_{A B q r} P_{A B} P_{q r}\right)= \\
& T_{A B A A} P_{A B} P_{A A}+T_{A B A B} P_{A B} P_{A B}+T_{A B A C} P_{A B} P_{A C}+T_{A B B A} P_{A B} P_{B A}+T_{A B B B} P_{A B} P_{B B}+T_{A B B C} P_{A B} P_{B C}+ \\
& T_{A B C A} P_{A B} P_{C A}+T_{A B C B} P_{A B} P_{C B}+T_{A B C C} P_{A B} P_{C C}=T_{A B A A} \frac{20}{100} \frac{10}{100}+T_{A B A B} \frac{20}{100} \frac{20}{100}+T_{A B A C} \frac{20}{100} \frac{5}{100}+ \\
& T_{A B B A} \frac{20}{100} \frac{5}{100}+T_{A B B B} \frac{20}{100} \frac{15}{100}+T_{A B B C} \frac{20}{100} \frac{5}{100}+T_{A B C A} \frac{20}{100} \frac{10}{100}+T_{A B C B} \frac{20}{100} \frac{25}{100}+T_{A B C C} \frac{20}{100} \frac{5}{100}
\end{aligned}
$$

In this equation $T_{A B A A}$ should be calculated according to equation (3) as follows:

$$
\begin{aligned}
& T_{A B A A}=\sum_{k \in K} T_{A B A A}^{k}= \\
& T_{A B A A}^{A}+T_{A B A A}^{B}+T_{A B A A}^{C}=(\min (6.24 \mathrm{PM}, 6.24 \mathrm{PM})-\max (5.13 \mathrm{PM}, 5.06 \mathrm{PM}))+ \\
& (\min (6.17 \mathrm{PM}, 6.17 \mathrm{PM})-\max (5.07 \mathrm{PM}, 5.07 \mathrm{PM}))+ \\
& (\min (6.15 \mathrm{PM}, 6.15 \mathrm{PM})-\max (5.22 \mathrm{PM}, 5.17 \mathrm{PM}))=71 \mathrm{~min}+65 \mathrm{~min}+53 \mathrm{~min}=189 \mathrm{~min}
\end{aligned}
$$

Equation (11) denotes the total amount of time that a commuter from zone A to B would be able to interact in the entire metropolitan area with a commuter who works and lives in zone A. These two commuters can spend together $71 \mathrm{~min}, 65 \mathrm{~min}$ and $53 \mathrm{~min}$ in zone A, B and C, respectively. The total potential time available for after-work interaction between other commuter type pairs 
( $T_{A B A B}, T_{A B A C}, T_{A B B A}$ etc.) can be calculated analogously. So doing, it then follows that the social interaction potential associated with a daily commute from zone A to B is:

$$
\begin{aligned}
& M_{C A B}=189 \mathrm{~min} \cdot 0.02+194 \mathrm{~min} \cdot 0.04+179 \mathrm{~min} \cdot 0.01+178 \mathrm{~min} \cdot 0.01+183 \mathrm{~min} \\
& 0.0375+168 \mathrm{~min} \cdot 0.01+169 \mathrm{~min} \cdot 0.02+174 \mathrm{~min} \cdot 0.05+159 \mathrm{~min} \cdot 0.01=37,32 \mathrm{~min}
\end{aligned}
$$

Equation (12) denotes the contribution associated with the commuting flow from $\mathrm{A}$ to $\mathrm{B}$ to the overall social interaction potential in metropolitan region $c$. The other metrics of social interaction (i.e. $M_{c i}, M_{c j}$ and $M_{c k}$ ) can be calculated in a similar fashion. Importantly, one can already see that even for this simple example consisting of three zones, the computation gives rise to a large number of iterations. We will explain how we have dealt with this computational burden in the next section, after discussing the characteristics of the study area and the data.

\section{Data}

\subsection{Study area and context}

The study area consists of Flanders and Brussels Capital Region (hereafter simply referred to as Brussels). Flanders is the Dutch-speaking, northern half of Belgium (Figure 3). The area is far more densely populated than its southern, French-speaking counterpart (Wallonia) (Figure 4). Flanders is approximately 13,500 km² in size and has over 6 million inhabitants (i.e. about $60 \%$ of the Belgian population). Flanders is one of the six Central and Capital City Regions (CCC regions) of international economic importance in North-West Europe, alongside London, Paris, the Frankfurt Rhine-Main region, the Rhine-Ruhr region and Randstad Holland. Being one of the most densely urbanized areas in the world, Flanders forms a challenging study area to implement the approach outlined in section 2. While Brussels $\left(160 \mathrm{~km}^{2}\right)$ is part of neither Flanders nor Wallonia, it will be included in the analysis because of its huge importance in the context of commuting flows.

According to the Spatial Structure Plan of Flanders (RSV, 2004), the study area includes three metropolitan regions: Brussels, Antwerp and Ghent. The major nexus of economic development is formed in and along the connections between these metropolitan regions and is known as the Flemish Diamond. Brussels (over 1 million inhabitants) is the largest employment center in 
Belgium and is mainly characterized by service industries. The service industry is also strongly represented in the center of Antwerp (approximately 500,000 inhabitants). Furthermore, Antwerp accommodates one of the largest ports in Europe and constitutes an important petrochemical node, with seven of the ten largest chemical companies in the world having a production site in this area. Ghent (approximately 250,000 inhabitants) is a medium-sized city and particularly known as a research and development center. Beyond the Flemish Diamond, there are a number of other significant smaller urban regions which, together with Antwerp and Ghent, are termed 'central cities' (see Figure 4), referring to the fact that they serve as a central node for their surrounding areas in terms of employment, education, services, culture and recreation. The two most important non-metropolitan urban regions in Flanders are Bruges (120,000 inhabitants) and Leuven (95,000 inhabitants). The former is well-known as a tourist destination and for its port activities, in particular regarding roll-on-roll-off shipping and the transferal of new vehicles. The latter contains the largest Dutch speaking university and attracts the largest share employees in the creative and knowledge-based industry of all municipalities in the country. In order of decreasing population, the other central cities include Mechelen (81,000), Aalst $(80,000)$, Kortrijk (75,000), Hasselt (73,000), Sint-Niklaas $(71,000)$, Oostende $(69,000)$, Genk $(65,000)$, Roeselare $(57,000)$ and Turnhout $(41,000)$ (Figure 4).

The commute areas of the various urban regions in the polycentric patchwork of Flanders and Brussels overlap strongly. The average commuting distance in the study area amounts to $16 \mathrm{~km}$ (one way) (Verhetsel, et al., 2007). In recent years, there is a large and systematic rise in the average commuting distance: between the successive decennial censuses of 1991 and 2001, the average commuting distance has increased by more than $10 \%$ (Thomas, et al., 2008). Importantly, almost one fourth of all commuters in Belgium (i.e. persons working outside the municipality where one lives) have their destination in Brussels. Hence, Brussels is expected to be a focal point of after-work social interaction potential. However, while the high working density implies more people to socialize with, the longer commutes to Brussels will act counteractively by implying less time for social interaction. Apart from Brussels, other important employment centers with relatively more incoming than outgoing workers include Antwerp, Ghent, Liege, Zaventem (airport), Charleroi and Leuven. Residential areas with a high negative balance between the incoming and outgoing flow of workers are primarily located in the 
surroundings of the major employment centers. The lowest average commute times in the country can be found in the western part of Flanders.

The contemporary commuting structure in Belgium has been shaped historically by an array of intended anti-urban policies and socio-economic processes that have taken place since the Industrial Revolution. In brief, the development of a fine-meshed network of railway connections and the abolishment of charges to enter inner cities in the second half of the $19^{\text {th }}$ century drove many workers to the fringes of the cities that until then had had sharp boundaries - often materialized through medieval city walls. This wave of suburbanization was subsequently invigorated and institutionalized by a social tariff scheme for commuting by train and other policies that were aimed at keeping the working class away from the bad influences of the city and under the influence of the local clergyman (see De Decker, 2011 for an in-depth discussion of consecutive uban policies in Flanders). In the postwar era, increased affluence and a concomitant increase in mobility, changes in residential preferences and the rapid growth of the tertiary sector gave rise to urban flight and peri-urbanization in the form of detached, singlefamily housing on the countryside; processes which continue until today (Boussauw, et al., 2011a).

[insert Figure 3 here]

[insert Figure 4 here]

\subsection{Journey-to-work flow matrix}

The journey-to-work flow matrix for Flanders is derived from the MultiModal Model (MMM). The MMM is a macroscopic traffic simulation model commissioned by the Flemish government since 1998 (Boussauw, et al., 2011b; Verhetsel, et al., 2007). The model is calibrated on the basis of traffic count data, the decennial census and a region-wide activity-travel diary data set (OVG, 'Onderzoek VerplaatsingsGedrag'). It simulates the number of trips, disaggregated according to their purpose, that take place during a particular time window between any pair of traffic analysis zones (TAZs). For the current study, the simulated number of work trips made between 4 and 11 a.m. on an average weekday morning has been used as a proxy for the number of workers that commute from one TAZ to another. 
The MMM is essentially composed of five sub-models, one for each province of Flanders (i.e. Flemish Brabant, Antwerp, East Flanders, Limburg and West Flanders). Brussels is included in the sub-model of Flemish Brabant. Every sub-model is represented by a GIS layer that divides the considered province into small TAZs. While in densely populated areas TAZs largely correspond to census tracts, census tracts have been aggregated into a single TAZ in more peripheral parts of the province. The areas surrounding the considered province (i.e. Wallonia, France, The Netherlands, Germany, Luxembourg and the other Flemish provinces) are also represented in the GIS layer and divided in TAZs of which the size increases with increasing distance from the province under scrutiny. The GIS layers for every sub-model can be linked to the journey-to-work flow matrix by a unique identifier. The number of TAZs amounts to 1,404 in West Flanders, 2,007 in East Flanders, 2,059 in Limburg, 2,689 in Flemish Brabant and 3,320 in Antwerp. To obtain a detailed map of the potential for social interaction for Flanders, we have applied the proposed method to each of the five provincial journey-to-work subsets separately, normalized these by the number of TAZs, and spatially merged the results afterwards.

\subsection{Travel time matrix}

Free-flow travel times by car along the shortest path between the centroids of all pairs of TAZs in each provincial sub-model have been estimated using ESRI ${ }^{\circledR}$ 's $\operatorname{ArcGIS}^{\mathrm{TM}}$ Network Analyst. To this end, we have used the TeleAtlas ${ }^{\circledR}$ MultiNet $^{\mathrm{TM}}$ data set (version 2007.10). This data set contains a detailed topological representation of the Belgian road network built up by links and nodes to which various attributes such as turn restrictions, speed limit, and functional road classification are attached. In total, 28,491,867 shortest paths had to be calculated in order to construct five matrices of travel times between all possible pairs $(i, j)$ of TAZs of the different partitioning systems used in each provincial sub-model. The provincial travel time matrices are quasi-symmetrical meaning that in most cases travel time from $i$ to $j$ roughly equals travel time from $j$ to $i$.

As the above shortest path calculations generated intrazonal travel times equal to zero on the diagonal line of the travel time matrix, we have adopted the approach suggested by O'Kelly and Lee (2005) to approximate average intrazonal commute. The approach assumes that each zone has a circular shape such that the average intrazonal travel distance can be estimated backwards 
from the known zonal area. When assuming an equal distribution of trips across zones, this intrazonal travel distance equals the radius of a zone (Frost, et al., 1998; Horner, 2002):

$p_{i i}=\left(\frac{S_{i}}{\pi}\right)^{1 / 2}$

where $p_{i i}$ is the approximate average intrazonal distance, and $S_{i}$ is the area of zone $i$. Finally, $p_{i i}$ is converted into travel time by assuming an average travel speed of $60 \mathrm{~km} / \mathrm{hour}$.

\subsection{Assumptions}

It is important to clearly emphasize the limitations and assumptions underlying this study. First, as explained in section 3.3, travel costs will be expressed by car travel times. While the car is certainly the dominant commuting mode in Flanders and accounts for over $71 \%$ of all commuting trips (65\% as driver and $5 \%$ as passenger), the share of other transport modes is also substantial: bicycle (13\%), train (7\%), bus tram and metro (4\%), pedestrians $(3 \%)$ and motorbikes $(2 \%)$. Car use is relatively less dominant in major cities and along the coastal area where more public transit options are available and commuting distances are smaller (Verhetsel, et al., 2007). Second, congestion effects and parking problems have not been incorporated in this study. This may lead to an underestimation of commuting times (and thus an overestimation of social interaction potential), especially for those working in the metropolitan areas of Brussels, Antwerp and Ghent. Third, given the aggregate nature of the origin-destination matrices, we were unable to differentiate individuals (or zones) on the basis of their departure/arrival time from/at work/home. Hence, a uniform after-work time budget of 90 minutes has been assumed for all commuters in the study area. In other words, geographic proximity of commuting flows will be the main enabler of social interaction potential, while the incorporation of timing constraints is left for future work. Fourth, our approach does not account for the fact that some form of social interaction can also happen during the trip itself (e.g. in the car, on the train), which, for some people, may lead to an underestimation of their social interaction potential. Finally, only the after-work social interaction potential of employees is looked at in this paper; people who are not employed outside of the house have not been considered.

The principal reason why the above assumptions have been (had to be) made is the lack of appropriate data to adequately model these effects in Flanders. For example, estimations of 
working hours, congestion, parking times and the number of carpoolers are difficult to obtain in a sufficiently detailed form for the entire study area. Furthermore, the origin-destination matrices available to us can only distinguish between trip purposes not between transport modes. Also, the calculation of travel times by public transport and travel times of multi-modal trips would be very time-consuming and difficult given the large number of calculations (almost thirty million) that have to be performed. While the above limitations should definitely be addressed in the future when finer-grained data would be available for Flanders, we believe the assumptions are nonetheless reasonable in the framework of this first exploratory study, given that its purpose is to identify large-scale spatial trends rather than individual level differences in the potential for social interaction. Nevertheless, the reader should be cautioned that the results obtained may not necessarily hold under different assumptions.

\subsection{Computation}

The social interaction potential metric is a weighted average of all possible after-work spacetime prism intersections. A region of $N$ zones has $N^{2}$ possible origin/destination pairs and the same number of possible space-time prisms. This gives rise to $N^{4}$ potential prism intersections. Since the volumes of the prisms are discretized over the $N$ zones of potential social activity, the number of computations required is in the order of $O\left(N^{5}\right)$. Thus a simple region with 100 zones may require 10 billion zone-based calculations; increase the complexity of the zoning system to 2000 zones, and the social interaction potential metric requires $3.2 \times 10^{16}$, or 32 million billion computations. In practice the number of calculations is reduced by pre-screening the origin/destination matrix for non-zero flows. Even with this reduction, practical computation of the metric necessitates a high performance computing infrastructure.

The metrics of social interaction potential were computed using the clustered computing facilities of The Center for High Performance Computing at The University of Utah (http://chpc.utah.edu). The Ember Cluster used in this analysis consists of 262, $2.8 \mathrm{GHz}, 12$-core nodes, giving rise to 3,144 total cores with 6,288 GB of total memory. This system enables fast computation of highly parallelizable tasks. For example, using 768 simultaneous cores, the system computed the full cadre of metrics for Antwerp in 2 hours 35 minutes, for Flemish Brabant in 2 hours and 30 minutes, for East Flanders in 36 minutes and West Flanders in 8 minutes. Similarly, using 960 cores, the metrics for Limburg were computed in 13 minutes. The 
computational overhead required to partition the problem into parallel components and assemble the results into a unified output matrix is negligible. This means that the time required to compute the metrics is perfectly proportional to the number of processors used. So, for example, doubling the resources used for Antwerp would likely result in a total computation time of only 1 hour and 20 minutes, while reducing the number of processors to one - in order to simulate the use of a single-core desktop computer - would result in a total computation time of nearly 83 days.

\section{Results}

\subsection{Social interaction potential in Flanders}

First we explore the general spatial structure of social interaction potential of commuters in Flanders using the four different metrics specified in section 2.2 (i.e. $M_{c i}, M_{c j}, M_{c k}$ and $M_{c i j}$ ). Given the extreme values obtained at the center of Brussels, the values of the different metrics have been categorized and visualized in quantiles to keep sufficient spatial variation in the figures. Figure 5 depicts the spatial variation in $M_{c i}$ (represented per zone of residence $i$ ) - that is it shows how socially sustainable it is to live at a particular location in Flanders given the realized commuting flows as well as the land-use and transport system in the area. Figure 5 shows a clearly articulated spatial structure for $M_{c i}$. The highest values are encountered in and around the Flemish Diamond formed by the mutually well-connected metropolitan areas of Brussels, Antwerp and Ghent. This is not surprising given the high population density and the large number of people who commute to these cities on a daily basis. Social interaction potential is also relatively high for those living in the core of the central cities as well as in some major cities along the Belgian coast, despite their eccentric location in the study area. Residential areas that exhibit poor levels of social interaction levels, on the other hand, can be found in the western and north-eastern corner of Flanders, close to the French and Dutch border, respectively. Knowing that the average commuting distance in the south-western part of Flanders is lower than elsewhere in the study area, it appears that the influence of commuting distance on social interaction potential is overcompensated by the relatively low density of both jobs and residents, as well as the absence of important highways in this area. 
To gain insight into the difference between the social interaction potential associated with either living or having a job in Flanders, Figure 6 compares the spatial pattern of $M_{c i}$ to that of $M_{c j}$. One can observe that in Brussels and the central cities, the average social interaction potential of workers is generally higher than that of residents - especially in the city center, industrial zone and/or port of these cities, where a large number of jobs are concentrated. The same is true for recreation areas (i.e. parks, forests etc.) where fewer (if any) people live than work.

The spatial variation of $M_{c k}$ (i.e. the expected potential demand for after-work social interaction) is represented in Figure 7. In other words, Figure 7 shows how probable it is that after-work social contact can take place between any two commuters at a particular location in Flanders. The spatial pattern resembles a more pronounced version of that of $M_{c i}$. There is a sharp contrast in potential social demand between the values in Brussels and those encountered in smaller cities. The high density of prism intersections in Brussels resonates, among others, the location strategy of various lobby organizations for which informal after-work social contacts with decision makers are paramount. Taken together, the demand for after-work social interaction can attain the highest levels at locations in the central part of the study area where the potential convergence of commuting flows is large.

\section{[insert Figure 5 here]}

\section{[insert Figure 6 here]}

\section{[insert Figure 7 here]}

To further explore why some regions may have higher (lower) social interaction potential than can otherwise be explained by the density of the working population, we have regressed social interaction potential on a selection of potential explanatory variables related to commuting and urban form. These variables include density of the working population ${ }^{1}$ (dens), job-housing balance $^{2}(j h b)$, spatial-functional diversity ${ }^{3}(d i v)$, average commuting distance (avgd),

\footnotetext{
${ }^{1}$ The number of departing commuting trips per $\mathrm{km}^{2}$ is used as a proxy for the density of workers in an area.

${ }^{2} \mathrm{jhb}$ is calculated as the ratio of the number of arriving commuting trips and the number of departing commuting trips.

${ }^{3}$ div of zone $i$ is calculated by means of a Shannon index as $d i v_{i}=-\sum_{n=1}^{N} p_{n} \cdot \ln p_{n}$, where $N$ is the number of different land-uses in zone $i$ and $p_{n}$ is the share of the total area of zone $i$ occupied by land-use $n$. Land-uses were derived from STRUCTNET, a data set produced by the Belgian National Geographical Institute (NGI) containing all
} 
(Euclidean) distance to highway (dhigh) and (Euclidean) distance to major city center ${ }^{4}$ (dcen). We checked whether any of the variables were strongly correlated with one another $(r>0.4)$; this turned out not to be the case. However, Moran's I and Lagrange Multiplier (LM) test statistics revealed that there is significant spatial dependence in the variables ('spatial lag') and/or errors terms ('spatial error') of a traditional OLS regression model. This may, among others, be due to the fact that the boundaries for which the data has been gathered do not reflect the nature of the underlying processes. Both LM-lag and LM-error test statistics are highly significant, with the latter more so. Hence, a spatial autoregressive model that corrects for spatial error was adopted. Three separate spatial error models were run using Geoda 0.9.5-i (Anselin et al., 2005), with $M_{c i}$, $M_{c j}$ and $M_{c k}$ as dependent variable, respectively. A queen connectivity structure was used to construct the contiguity weight matrix - that is, zones are considered neighboring if their boundaries have at least one point in common. In each of the three models, an increase in log likelihood and a decrease for the Akaike info criterion was observed, suggesting an improvement of fit over the OLS model. The results of the spatial regression models are shown in Table 1.

The spatial autoregression coefficient lambda has a positive effect and is highly significant in each of the models. When density of the working population is controlled for, a higher level of $M_{c i}$ is associated with a low job-housing balance and low average commuting distance $(\mathrm{p}<$ 0.01). The level of $M_{c j}$, on the other hand, increases with increasing density of the working population, spatial-functional diversity and job-housing balance $(\mathrm{p}<0.01)$. Surprisingly, proximity to a major city center and distance to a highway does not have a significant influence on $M_{c i}$ and $M_{c j}$ when other factors of commuting and urban form are taken up in the spatial regression model. This is different in the model with $M_{c k}$ as dependent variable. $M_{c k}$ was found to be positively associated with density, diversity, job-housing balance, distance to transportation infrastructure and proximity of central cities, while the average commuting distance did not show a significant effect on $M_{c k}(\mathrm{p}<0.01)$. The pseudo $R^{2}(0.984)$ for the $M_{c k}$ model is much higher than that of $M_{c i}(0.554)$ and $M_{c j}(0.544)$, suggesting a better model fit. Also, the relatively high coefficient of dcen indicates that the demand for social interaction is primarily determined by the proximity of a major city center (see also Figure 7).

buildings present on the Belgian topographic maps of scale 1:10 000, along with their categorization (i.e. industry, school, hospital, public service etc.).

${ }^{4}$ Major cities in Flanders included the thirteen central cities and Brussels. 
[insert Table 1 here]

\subsection{Social interaction potential associated with a given commute}

Besides this overall spatial structure of $M_{c i}, M_{c j}$ and $M_{c k}$, we have also explored how $M_{c i j}$ may add to our understanding of the geography of social interaction potential. Since this metric presumes an a priori type of commute from $i$ to $j$, this exploration can only be done anecdotally. Hence, Figure 8 and 9 show an example of the amount of opportunity for social interaction for people living at a particular location in East Flanders while working in the inner city of Ghent. In other words, the maps represent where workers in the inner city should reside to attain a particular level of social interaction potential. It should be noted however that if no commute is observed between a zone and the inner city (i.e. $P_{i j}=0$ in equation (8)), then the metric attains zero, indicating that there is no contribution of that zone's population to the aggregate measurement of social interaction potential. For the remaining zones, we have expressed $M_{c i j}$ in two ways: per square kilometer (Figure 8) and per person (Figure 9). The former shows a zone's absolute contribution to $M_{c j}$ of the inner city, while the latter depicts each zone's contribution after controlling for the influence of the size of the working population. Generally, social interaction potential decreases with increasing distance between the home location and the inner city, with the effect of proximity being more articulated after controlling for the size of the working population. This means that workers who have a longer commute tend to have less social contact options. However, it also appears that even for those having a longer commute, living in an urban environment is more beneficial for social interaction potential than living in a rural environment. Therefore, planning additional residential areas in small urban areas may be a valid policy intervention from a social sustainability point of view, even if these urban areas have a low job-housing balance.

Zones with a large absolute contribution to the social potential of workers in the inner city are primarily encountered in other neighborhoods in Ghent surrounding the inner city - the port area being the exception - as well as in mainly residential municipalities such as Lovendegem, Evergem, Nazareth and Gavere (see Figure 8); municipalities which are primarily reliant on services and jobs in Ghent. This example illustrates that this type of analysis may for example be useful to inform policy makers' decision about the social sustainability of location alternatives 
for new residential neighborhoods, provided that the work location of prospective inhabitants is known.

Taken together, Figures 5-9 show that there are marked differences in the potential to interact with others in Flanders. Depending on the metric used, the geography of the social potential associated with a particular home location, work location or commute pattern can be explored.

\section{[insert Figure 8 here]}

[insert Figure 9 here]

\subsection{Social interaction potential within major cities}

Having explored the general spatial structure of the potential for social contact, we will now examine the differences of this potential within and between major cities in the study area using exploratory spatial data analysis (ESDA). In particular, we will use Anselin's (1995) local indicator of spatial autocorrelation (LISA) to identify statistically significant clusters and outliers in the geography of social interaction potential. The result of this analysis yields five cluster types: "high-high", "low-low", "low-high", "high-low" and "not significant". A high-high cluster indicates spatial clustering of high values, whereas a low-low cluster indicates spatial clustering of low values. These cluster types reflect positive spatial autocorrelation or local spatial clustering of similar values. Likewise, a low-high outlier implies that low values of social interaction potential are associated with high neighboring values, whereas a high-low outlier implies that high values of social interaction potential are associated with low neighboring values. These outliers are equivalent to negative spatial autocorrelation as they point to locations that are different from their neighbors in terms of social interaction potential. Finally, the category "not significant" refers to the absence of spatial dependence - that is, the spatial pattern of social interaction potential does not differ statistically from what could have been expected from a random spatial distribution.

The LISA ${ }^{5}$ clusters and outliers of $M_{c i}, M_{c i}-M_{c j}$, and $M_{c k}$ are shown in Figure 10 for Brussels and the four largest cities in Flanders (Antwerp, Ghent, Bruges and Leuven). With regard to the

\footnotetext{
${ }^{5}$ The clusters and outliers have been calculated using an inverse distance weighting scheme: all features impact all other features but the farther away, the smaller the impact. Other schemes to specify how spatial relationships among features are conceptualized were tested, but did result in similar patterns.
} 
social potential of a residential location $\left(M_{c i}\right)$, low-low clustering is primarily observed in peripheral and port areas. This is for example clearly visible for Antwerp and Bruges. High-high clusters of $M_{c i}$ can primarily be found in the historical centers of the cities (except in Brussels), supporting the conjecture that compact living increases the social interaction possibilities of a neighborhood. In Brussels however, high-high clusters of $M_{c i}$ environ the historical center, while the center itself is mainly dominated by low-low clusters of $M_{c i}-M_{c j}$. This is because the historical center contains many neighborhoods where the number of jobs strongly outweighs the number of residents (Riguelle, et al., 2007). This job-housing imbalance is, to a smaller degree, also observable in Antwerp and Ghent where many low-low clusters of $M_{c i}-M_{c j}$ are encountered in the city center. In Ghent, low-low clustering of $M_{c i}-M_{c j}$ is additionally present at the intersection of two important highways where many employment opportunities are concentrated. In Bruges and Leuven, on the other hand, we find low-high outliers at clearly distinguishable areas in the city. After closer inspection of these areas, it appears that these correspond to industrial sites, in the case of Bruges, and the university campus and the hospital, in the case of Leuven, where the contribution to social potential stems from workers rather than inhabitants. Finally, regarding the total amount of social interaction opportunity that can take place in the city $\left(M_{c k}\right)$, some well-defined pockets of high-high clustering can be observed in the historical centers of the considered cities. These pockets designate areas where social interaction intensity is expected to be very high.

In addition to these internal spatial differences, we can also compare cities in terms of their contribution to the overall social interaction potential in the study area. In order for the reader to get a feel of the spatial structure of the considered cities, Table 2 summarizes the cities' contributions to $M_{c i}$ and $M_{c j}$ in the study area, the sum of social interaction potential over all TAZs in a city, the coefficient of variation ${ }^{6}$ in social interaction potential across these TAZs, as well as some important city characteristics including area, population size, road network density, number of origins/destinations of commuting trips, average commuting distance and residence/employment density gradients ${ }^{7}$.

\footnotetext{
${ }^{6}$ The coefficient of variation is a normalized, dimensionless measure of statistical dispersion that is calculated as the ratio of the standard deviation to the mean.

${ }^{7}$ Following Li (2010), these density gradients have been determined using a negative exponential density function: $D=D_{0} e^{-\gamma s}$, where $D$ is the residential/employment density; $D_{0}$ is the residential/employment density at the city
} 
Figure 11 shows the contribution to the total $M_{c i}$ and $M_{c j}$ produced by each of the central cities ${ }^{8}$. In total, the central cities account for $21 \%$ of $M_{c i}$ and $26 \%$ of $M_{c j}$ in the study area (Figure 11). This difference tends to suggest that the employment function of the central cities is more important than their residential function. However, the social interaction potential of workers is more varied than that of residents (Table 2) and may in part be explained by the fact that the distribution of jobs is more centralized than the distribution of residents as indicated by the density gradients. The contribution of Brussels to the social interaction potential in the region equals over one fifth for $M_{c i}$ and one third for $M_{c j}$ (Table 2), emphasizing the major role of Brussels as employment center. It also implies that the longer commute distances to Brussels (Table 2) are strongly inferior to the effect of the high residential and working density. Of all central cities, Antwerp provides by far the most opportunities for social interaction for both workers and residents, followed by Ghent and Leuven. Social interaction potential in these cities is supported by a dense transport infrastructure.

Evidently, a city's contribution to the overall interaction potential within the study area depends largely on its population size. Therefore, we have divided a city's relative contribution by the proportion of people living and working in that city for $M_{c i}$ and $M_{c j}$, respectively. This enables to explore whether the contribution of a city to the overall interaction potential in the study area deviates from what could have been expected on the basis of its population share in the study area. Table 2 shows that the contribution of Brussels to $M_{c i}$ is one and a half times as much as what could have been expected based on its residential population share. The normalized contribution of to the overall $M_{c j}$, on the other hand, is even 2 and a half times larger than expected. Of all central cities, Leuven makes the largest contribution to the overall social interaction potential relative to what is expected (Figure 12), presumably owing to its proximity to Brussels. This is also true for Aalst, Ghent, Antwerp and Sint-Niklaas. Aalst, which has a very low job-housing balance, is the only city for which the normalized contribution to $M_{c j}$ exceeds that to $M_{c i}$. Roeselare, Kortrijk, Hasselt, Genk, Bruges, Turnhout and Oostende, for their part, are less sustainable in terms of social interaction potential for both living and working. Interestingly, thus, even after controlling for population size, cities within or close to the Flemish

center; $\gamma$ is the density gradient and $s$ is the Euclidean distance to the city center. The larger the density gradient, the more centralized the urban spatial distribution of residences/employment is.

${ }^{8}$ For visual purposes, the contribution of Brussels is not shown in Figure 11 and 12, given its outlying value. 
Diamond still provide more social interaction possibilities than more peripheral cities in the region, notwithstanding the longer commutes to these cities.

[insert Figure 10 here]

[insert Figure 11 here]

[insert Figure 12 here]

\section{Conclusion}

This paper has shed new light on the contested relationship between urban spatial structure and social interaction. The study differs in at least two important aspects from earlier empirical studies in this area, which have predominantly concentrated on the analysis of realized social behavior at the level of residential neighborhoods. First, this study has focused on potential rather than realized social behavior. This shift in focus is motivated by the believe that increasing individuals' opportunities for social interaction can more easily be achieved through transport and land-use policy than the manipulation of their preferences and actual choices - a stance that has long since been defended in time-geographic work. Second, the method applied in this paper enables to study social contact at a much larger scale (i.e. the scale of an entire metropolitan region) and accounts for potential social behavior outside the residential neighborhood.

Our findings clearly showed that there is a strong relationship between urban spatial structure and the potential for social interaction. In general, it was found that the opportunities for afterwork social contact depend on (working) population density, diversity, average commuting distance and job-housing balance. The demand for social interaction, on the other hand, was found to be positively associated with proximity to major city centers, distance to transportation infrastructure, density, diversity and job-housing balance. Given the centrality of city economics in the study area, locations with a significantly high potential for social interaction are spatially concentrated in the historical centers of major Flemish cities and Brussels. Besides spatial intracity differences, we also observed important mutual differences in social interaction potential. Cities located near the economic nexus of the study area provide more social interaction opportunities for both residents and workers, even after controlling for their residential and working population shares. 
The above findings should however be seen in light of the well-acknowledged limitations discussed in section 3.4. While addressing these already constitutes an important first avenue for future work, several advancements of the methodology also come to the fore. One potential advancement is to refine the metrics proposed in this paper by incorporating such aspects as travel time decay, timing preferences (see e.g. Neutens, et al., 2010a) and the spatial distribution of urban facilities for social interaction (e.g., restaurants, bars, sports accommodations etc.). Another is to measure social interaction potential at a more disaggregated level. This can be realized by deriving individuals' prism constraints (i.e. home/work locations and start/end times at work) from activity-travel diaries. By combining this information with aggregate commuting flow data, we would be able to calculate the social interaction potential of each respondent of the travel diary data set, given the realized commuting flows in the area. We can then examine whether these individual-based interaction metrics are good predictors of the propensity to conduct social activities and the locations where these are taking place. Alternatively, one can draw on social network data of ego-alter relations (see e.g. Carrasco and Miller, 2009). As this type of data generally provides the home and work locations of a respondent's social activity partners, it can be investigated how spatio-temporal constraints affect a person's ability to interact with his/her social network. Finally, additional efforts are necessary to compare our findings with those in other regional contexts, including non-European cities with different morphologies. It is our intention to address these and related issues in the near future.

\section{Acknowledgements}

Tijs Neutens gratefully acknowledges the Research Foundation Flanders (FWO) for financial support. 


\section{References}

Anselin, L. (1995). Local indicators of spatial association - LISA. Geographical Analysis, 27, 93-115.

Anselin, L., I. Syabri and Kho, Y. (2005). GeoDa : An Introduction to Spatial Data Analysis. Geographical Analysis, 38, 5-22.

Bordieu, P. (1986.) The Forms of Capital, in J. G. Richardson (ed.) Handbook of Theory and Research for the Sociology of Education, New York: Greenwood Press: 241-258.

Boussauw, K., Derudder, B., \& Witlox, F. (2011a). Measuring Spatial Separation Processes through the Minimum Commute: the Case of Flanders. European Journal of Transport and Infrastructure Research, 11, 42-60.

Boussauw, K., Neutens, T., \& Witlox, F. (2011b). Minimum commuting distance as a spatial characteristic in a non-monocentric urban system: The case of Flanders. Papers in Regional Science, 90, 47-66.

Brueckner, J. K., \& Largey, A. G. (2008). Social interaction and urban sprawl. Journal of Urban Economics, 64, 18-34.

Carrasco, J.A., Miller, E.J., 2009. The social dimension in action: a multilevel, personal networks model of social activity frequency between individuals. Transportation Research Part A: Policy and Practice, 43, 1, 90-104.

Coleman, J. 1988. Social Capital in the Creation of Human Capital, American Journal of Sociology, 94, S95-121.

Cullen, I., \& Godson, V. (1975). Urban networks: The structure of activity patterns. Progress in Planning, 4, 1-96.

De Decker, P. (2011). Understanding housing sprawl: the case of Flanders, Belgium. Environment and Planning A, 43, 1634-1654.

Fang, Z., Tu, W., Li, Q., \& Li, Q. (2011). A multi-objective approach to scheduling joint participation with variable space and time preferences and opportunities. Journal of Transport Geography, 19, 623-634.

Farber, S., Neutens, T., Miller, H. J., \& Li, X. (2012). Social interaction potential of metropolitan regions: a time-geographic measurement approach using joint accessibility. Annals of the Association of American Geographers, (In press).

Farber, S., \& Paez, A. (2009). My car, my friends, and me: a preliminary analysis of automobility and social activity participation. Journal of Transport Geography, 17, 216225.

Farber, S., \& Paez, A. (2011). Running to stay in place: the time-use implications of automobile oriented land-use and travel. Journal of Transport Geography, 19, 782-793.

Forrest, R., \& Kearns, A. (2001). Social cohesion, social capital and the neighbourhood. Urban Studies, 38, 2125-2143.

Freeman, L. (2001). The effects of sprawl on neighborhood social ties - An explanatory analysis. Journal of the American Planning Association, 67, 69-77.

Frost, M., Linneker, B., \& Spence, N. (1998). Excess or wasteful commuting in a selection of British cities. Transportation Research Part a-Policy and Practice, 32, 529-538.

Guest, A. M., \& Wierzbicki, S. K. (1999). Social ties at the neighborhood level - Two decades of GSS evidence. Urban Affairs Review, 35, 92-111.

Hägerstrand, T. (1970). What about people in regional science? Papers of the Regional Science Association, 24, 7-21. 
Horner, M. W. (2002). Extensions to the concept of excess commuting. Environment and Planning A, 34, 543-566.

Jacobs, J. (1961). The death and life of great American cities. New york: Vintage.

Kang, H., \& Scott, D. M. (2008). An integrated spatio-temporal GIS toolkit for exploring intrahousehold interactions. Transportation, 35, 253-268.

Kwan, M. P., \& Hong, X. D. (1998). Network-based constraint-oriented choice set formation using GIS. Journal of Geographical Systems, 5, 139-162.

Kwan, M. P., \& Lee, J. Y. (2011). Visualisation of socio-spatial isolation based on human activity patterns and social networks in space-time. Tijdschrift voor Economische en Sociale Geografie, 102, 468-485.

Lenntorp, B. (1978). A time-geographic simulation model of individual activity programmes. In T. Carlstein, D. Parkes \& N. Thrift (Eds.), Timing Space and Spacing Time, Human Activity and Time Geography (Vol. 2, pp. 162-180). London: Edward Arnold.

Leyden, K. M. (2003). Social capital and the built environment: The importance of walkable neighborhoods. American Journal of Public Health, 93, 1546-1551.

Li, S.-M. (2010). Evolving residential and employment locations and patterns of commuting under hyper growth: The case of Guangzhou, China. Urban Studies, 47, 1643-1661.

Lund, H. (2003). Testing the claims of new urbanism - Local access, pedestrian travel, and neighboring behaviors. Journal of the American Planning Association, 69, 414-429.

Miller, H. J. (2005a). A measurement theory for time geography. Geographical Analysis, 37, $17-$ 45.

Miller, H. J. (2005b). Necessary space-time conditions for human interaction. Environment and Planning B-Planning \& Design, 32, 381-401.

Neutens, T., Schwanen, T., \& Miller, H. J. (2010a). Dealing with timing and synchronization in opportunities for joint activity participation. Geographical Analysis, 42, 245-266.

Neutens, T., Schwanen, T., Witlox, F., \& De Maeyer, P. (2008). My space or your space? Towards a measure of joint accessibility. Computers, Environment and Urban Systems, 32, 331-342.

Neutens, T., Versichele, M., \& Schwanen, T. (2010b). Arranging place and time: A GIS toolkit to assess individual and joint accessibility to urban opportunities. Applied Geography, 30, 561-575.

Nguyen, D. (2010). Evidence of the impacts of urban sprawl on social capital. Environment and Planning B-Planning \& Design, 37, 610-627.

O'Kelly, M. E., \& Lee, W. (2005). Disaggregate journey-to-work data: implications for excess commuting and jobs-housing balance. Environment and Planning A, 37, 2233-2252.

Putnam, R. D. (2000). Bowling Alone: The collapse and revival of American community. New York: Simon \& Schuster.

Riguelle, F., Thomas, I., \& Verhetsel, A. (2007). Measuring urban polycentrism: a European case study and its implications. Journal of Economic Geography, 7, 193-215.

Rostila, M. (2010). The Facets of Social Capital. Journal for the Theory of Social Behaviour, 41, $3, .308-326$.

RSV. (2004). Ruimtelijk structuurplan Vlaanderen - Gecoördineerde versie. In. Brussels: Ministry of the Flemisch Community.

Salze, P., Banos, A., Oppert, J.-M., Charreire, H., Casey, R., Simon, C., Chaix, B., Badariotti, D., \& Weber, C. (2011). Estimating spatial accessibility to facilities on the regional scale: an 
extended commuting-based interaction potential model. International Journal of Health Geographics, 10.

Sander, T. H. (2002). social capital and new urbanism: Leading a civic horse to water? National civic Review, 91, 213-234.

Talen, E. (2002). The social goals of new urbanism. Housing Policy Debate, 13, 165-188.

Thomas, I., Verhetsel, A., \& Beelen, M. (2008). Quand la Belgique se réveille. Les Echos du Logement, 2, 34-40.

Verhetsel, A., Thomas, I., Van Hecke, E., \& Beelen, M. (2007). Pendel in België. Deel I: WoonWerkverplaatsingen. In: Federal Public Service Economy.

Yu, H., \& Shaw, S. L. (2008). Exploring potential human activities in physical and virtual spaces: a spatio-temporal GIS approach. International Journal of Geographical Information Science, 22, 409-430. 


\section{Tables}

Table 1. Results of spatial error regression model.

\begin{tabular}{|c|c|c|c|c|c|c|c|c|c|c|c|}
\hline \multicolumn{2}{|c|}{ Dependent variable: $M_{c i}$} & \multirow[b]{2}{*}{ Std. Error } & \multirow[b]{2}{*}{$\mathrm{p}$-value } & \multicolumn{2}{|c|}{ Dependent variable: $M_{c j}$} & \multirow[b]{2}{*}{ Std. Error } & \multirow[b]{2}{*}{$\mathrm{p}$-value } & \multicolumn{2}{|c|}{ Dependent variable: $M_{c k}$} & \multirow[b]{2}{*}{ Std. Error } & \multirow[b]{2}{*}{$\mathrm{p}$-value } \\
\hline Variable & Coefficient & & & Variable & Coefficient & & & Variable & Coefficient & & \\
\hline Constant & 0.846 & 0.064 & 0.000 & Constant & 0.629 & 0.096 & 0.000 & Constant & 1.630 & 0.040 & 0.000 \\
\hline dens & 0.775 & 0.023 & 0.000 & dens & 0.918 & 0.036 & 0.000 & dens & 0.019 & 0.005 & 0.000 \\
\hline div & -0.055 & 0.028 & 0.047 & div & 0.173 & 0.044 & 0.000 & div & 0.010 & 0.004 & 0.008 \\
\hline jhb & -0.128 & 0.030 & 0.000 & jhb & 0.778 & 0.048 & 0.000 & jhb & 0.019 & 0.004 & 0.000 \\
\hline avgd & -0.157 & 0.037 & 0.000 & avgd & -0.129 & 0.058 & 0.026 & avgd & 0.003 & 0.006 & 0.671 \\
\hline dhigh & 0.071 & 0.049 & 0.151 & dhigh & 0.087 & 0.077 & 0.258 & dhigh & -0.096 & 0.009 & 0.000 \\
\hline dcen & -0.103 & 0.062 & 0.099 & dcen & -0.227 & 0.094 & 0.016 & dcen & -0.369 & 0.024 & 0.000 \\
\hline lambda & 0.575 & 0.012 & 0.000 & lambda & 0.546 & 0.012 & 0.000 & lambda & 0.975 & 0.001 & 0.000 \\
\hline \multicolumn{4}{|c|}{ Pseudo $R^{2}=0.554 ; N=6668$} & \multicolumn{4}{|c|}{ Pseudo $R^{2}=0.544 ; N=6668$} & \multicolumn{4}{|c|}{ Pseudo $R^{2}=0.984 ; N=6668$} \\
\hline
\end{tabular}


Table 2. Social interaction potential and city characteristics.

\begin{tabular}{|c|c|c|c|c|c|c|c|c|c|c|c|c|c|c|c|c|c|c|}
\hline City & $\begin{array}{l}\text { Contribution } \\
\text { to Mci }\end{array}$ & $\begin{array}{l}\text { Contribution } \\
\text { to Mcj }\end{array}$ & $\begin{array}{l}\text { Contribution } \\
\text { to Mci } \\
\text { relative to } \\
\text { expectation }\end{array}$ & $\begin{array}{l}\text { Contribution } \\
\text { to Mcj } \\
\text { relative to } \\
\text { expectation }\end{array}$ & $\begin{array}{l}\text { Sum } \\
\text { of } \\
\text { Mci }\end{array}$ & $\begin{array}{l}\text { Sum } \\
\text { of } \\
\text { Mcj }\end{array}$ & $\begin{array}{l}\text { Coefficient } \\
\text { of } \\
\text { variation } \\
\text { in Mci }\end{array}$ & $\begin{array}{l}\text { Coefficient } \\
\text { of } \\
\text { variation } \\
\text { in } \mathrm{Mcj}\end{array}$ & $\begin{array}{l}\text { Area } \\
\left(\mathrm{km}^{2}\right)\end{array}$ & $\begin{array}{l}\text { Population } \\
\text { size }\end{array}$ & $\begin{array}{l}\text { Population } \\
\text { density } \\
\text { (inh/ } / \mathrm{km}^{2} \text { ) }\end{array}$ & $\begin{array}{l}\text { Road } \\
\text { network } \\
\text { density } \\
\left(\mathrm{km} / \mathrm{km}^{2}\right)\end{array}$ & $\begin{array}{l}\text { Number of } \\
\text { origins }\end{array}$ & $\begin{array}{l}\text { Number of } \\
\text { destinations }\end{array}$ & $\begin{array}{l}\text { Average } \\
\text { commuting } \\
\text { distance } \\
\text { outgoing } \\
\text { workers } \\
(\mathrm{km})\end{array}$ & $\begin{array}{l}\text { Average } \\
\text { commuting } \\
\text { distance } \\
\text { incoming } \\
\text { workers } \\
(\mathrm{km})\end{array}$ & $\begin{array}{l}\text { Residence } \\
\text { density } \\
\text { gradient }\end{array}$ & $\begin{array}{l}\text { Employment } \\
\text { density } \\
\text { gradient }\end{array}$ \\
\hline Aalst & $1.40 \%$ & $1.50 \%$ & $78.91 \%$ & $96.12 \%$ & 0.07 & 0.11 & 1.22 & 1.98 & 78.59 & 80,043 & 1,019 & 6.14 & 27,069 & 26,443 & 14.70 & 11.52 & 0.51 & 0.80 \\
\hline Antwerp & $6.30 \%$ & $8.41 \%$ & $72.12 \%$ & $56.12 \%$ & 1.17 & 1.65 & 0.94 & 1.72 & 203.74 & 483,505 & 2,373 & 8.01 & 145,337 & 214,075 & 12.71 & 17.60 & 0.38 & 0.45 \\
\hline Bruges & $0.89 \%$ & $1.09 \%$ & $-20.01 \%$ & $-21.64 \%$ & 0.08 & 0.10 & 0.79 & 1.48 & 130.08 & 116,741 & 897 & 6.25 & 40,007 & 50,080 & 17.37 & 14.27 & 0.48 & 0.41 \\
\hline Brussels & $22.45 \%$ & $33.11 \%$ & $145.73 \%$ & $262.38 \%$ & 2.00 & 4.63 & 0.79 & 1.37 & 161.38 & $1,136,920$ & 7,045 & 13.31 & 298,279 & 535,161 & 9.24 & 24.16 & 0.39 & 0.52 \\
\hline Genk & $0.46 \%$ & $0.56 \%$ & $-17.46 \%$ & $-18.76 \%$ & 0.02 & 0.02 & 1.02 & 1.81 & 87.85 & 64,757 & 737 & 6.55 & 19,668 & 24,349 & 17.15 & 13.49 & 0.61 & 0.82 \\
\hline Gent & $4.57 \%$ & $5.55 \%$ & $78.71 \%$ & $62.96 \%$ & 0.42 & 0.57 & 1.43 & 1.75 & 157.70 & 243,366 & 1,543 & 8.08 & 88,531 & 117,917 & 15.97 & 15.14 & 0.46 & 0.42 \\
\hline Hasselt & $0.62 \%$ & $0.91 \%$ & $-11.62 \%$ & $-15.66 \%$ & 0.05 & 0.09 & 1.19 & 2.42 & 103.21 & 73,067 & 708 & 5.91 & 24,751 & 38,166 & 16.67 & 14.72 & 0.59 & 0.98 \\
\hline Kortrijk & $0.68 \%$ & $0.92 \%$ & $-7.26 \%$ & $-10.45 \%$ & 0.07 & 0.12 & 0.99 & 1.90 & 80.89 & 74,911 & 926 & 7.55 & 26,423 & 36,974 & 12.81 & 12.45 & 0.45 & 0.74 \\
\hline Leuven & $2.66 \%$ & $2.82 \%$ & $108.52 \%$ & $80.09 \%$ & 0.31 & 0.48 & 1.30 & 1.70 & 57.48 & 95,463 & 1,661 & 9.59 & 41,625 & 51,198 & 14.96 & 16.95 & 0.76 & 0.93 \\
\hline Mechelen & $1.02 \%$ & $1.22 \%$ & $60.48 \%$ & $49.76 \%$ & 0.17 & 0.21 & 1.04 & 1.87 & 65.94 & 80,940 & 1,228 & 6.71 & 25,264 & 32,481 & 14.49 & 17.16 & 0.50 & 0.95 \\
\hline Oostende & $0.35 \%$ & $0.42 \%$ & $-36.38 \%$ & $-37.84 \%$ & 0.08 & 0.09 & 0.90 & 1.45 & 38.36 & 69,064 & 1,800 & 8.63 & 19,933 & 24,031 & 20.21 & 11.77 & 0.82 & 0.92 \\
\hline Roeselare & $0.54 \%$ & $0.63 \%$ & $-0.39 \%$ & $-6.49 \%$ & 0.05 & 0.07 & 0.82 & 1.53 & 60.53 & 57,432 & 949 & 7.22 & 19,545 & 24,208 & 12.27 & 11.31 & 0.62 & 0.94 \\
\hline Sint-Niklaas & $0.99 \%$ & $1.10 \%$ & $49.08 \%$ & $42.21 \%$ & 0.04 & 0.06 & 1.01 & 1.77 & 83.89 & 71,806 & 856 & 4.58 & 22,892 & 26,745 & 12.48 & 11.97 & 0.53 & 0.75 \\
\hline Turnhout & $0.30 \%$ & $0.37 \%$ & $-20.93 \%$ & $-36.00 \%$ & 0.03 & 0.03 & 0.95 & 1.54 & 56.52 & 40,763 & 721 & 5.60 & 15,196 & 22,840 & 14.56 & 14.08 & 1.01 & 1.09 \\
\hline
\end{tabular}




\section{Figures}

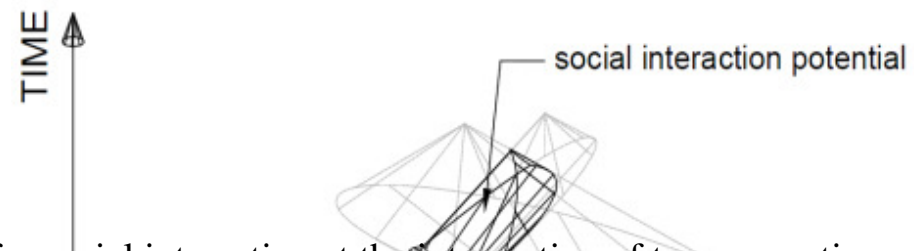

Figure 1. Potential for social interaction at the presection of two space-time prisms.

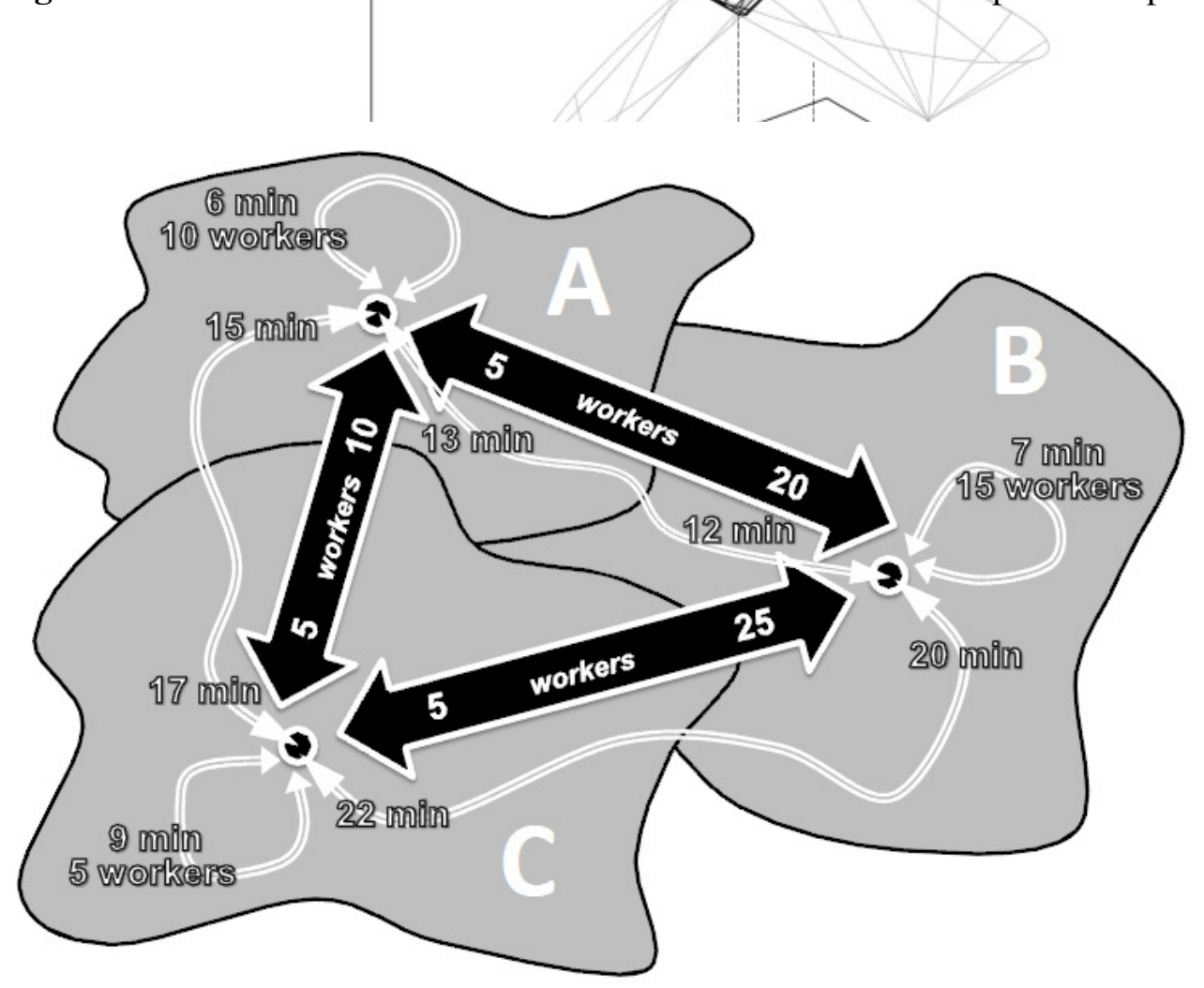

Figure 2. Calculation example. 


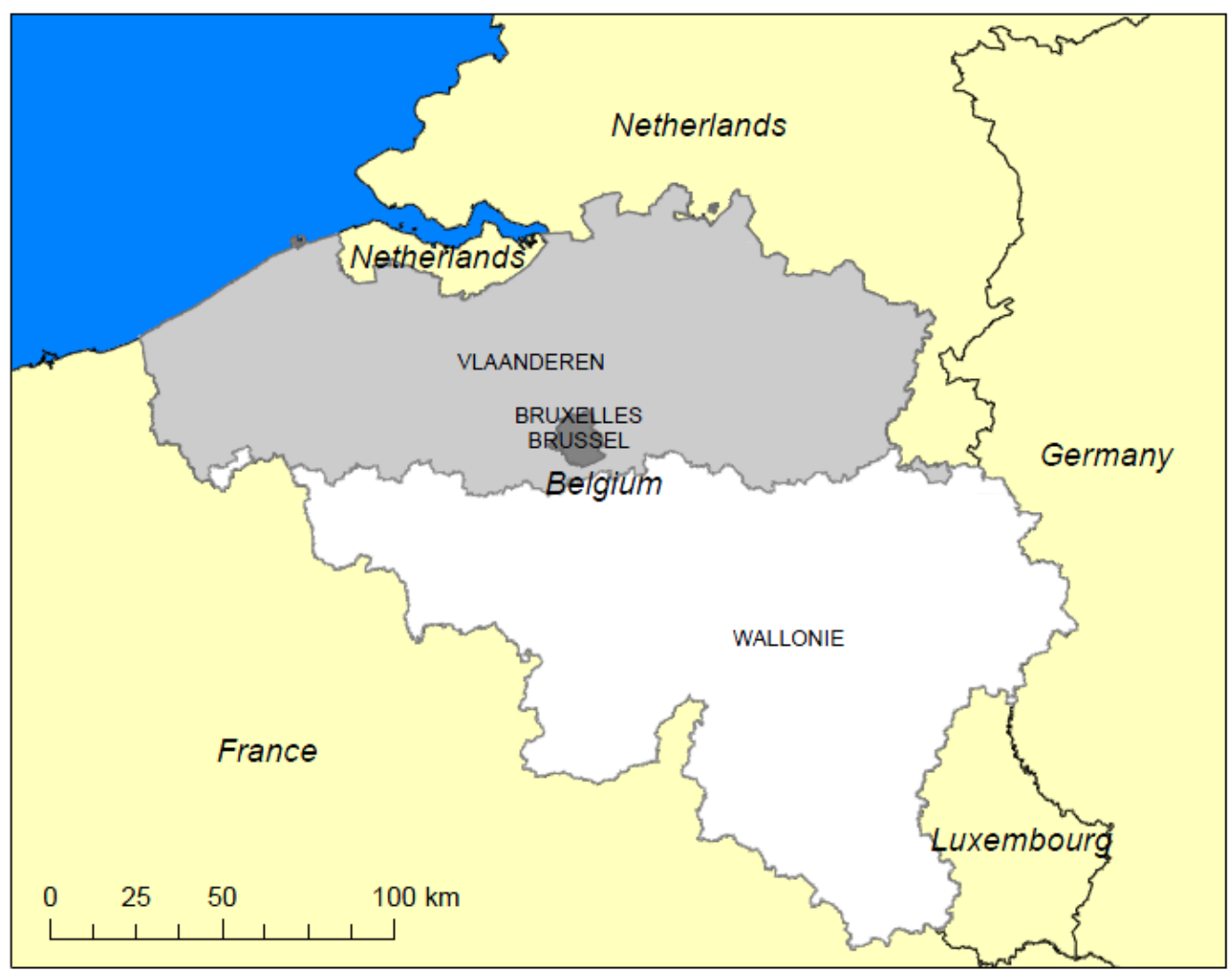

Figure 3. Study area.

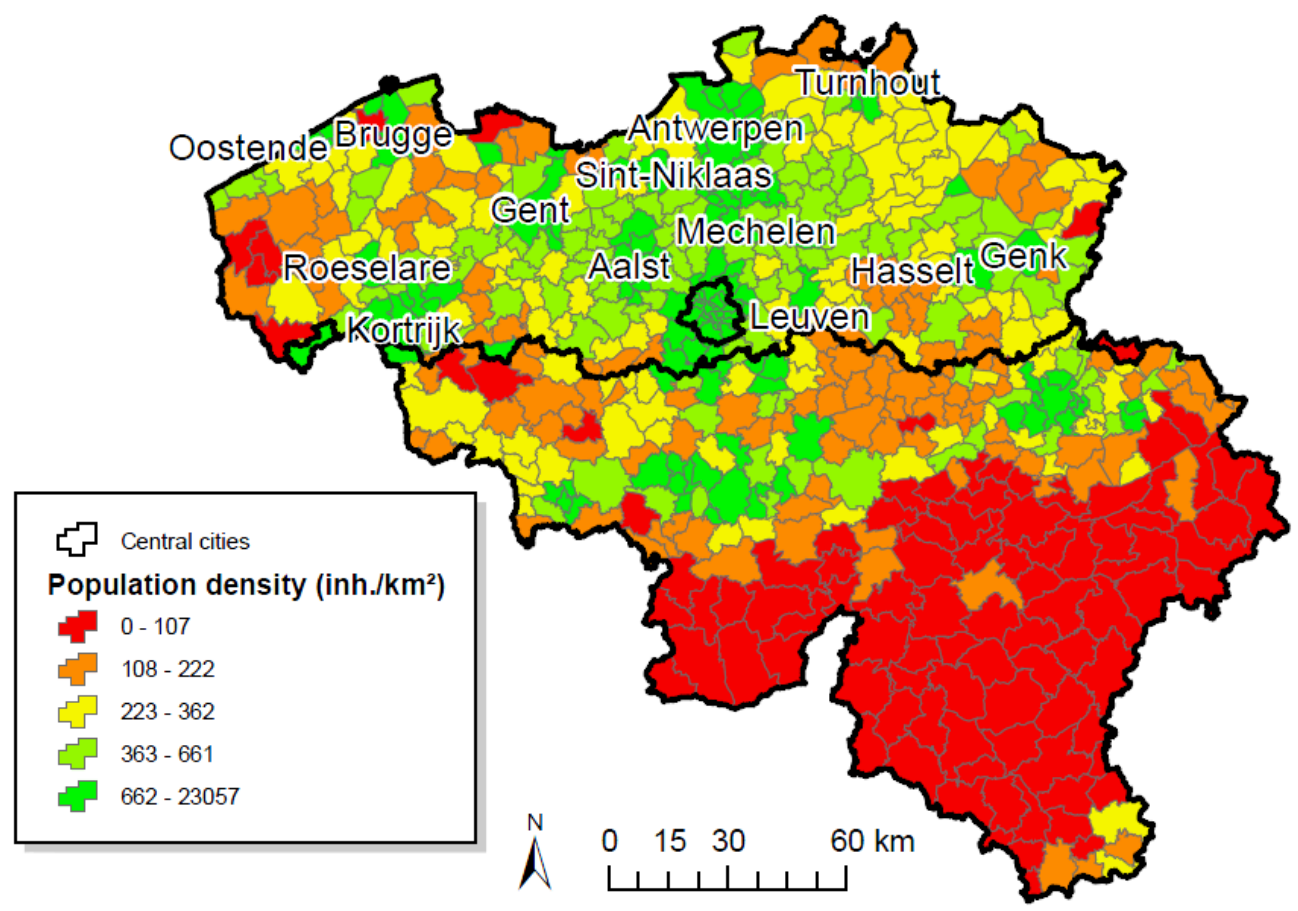

Figure 4. Population density in Belgium. 


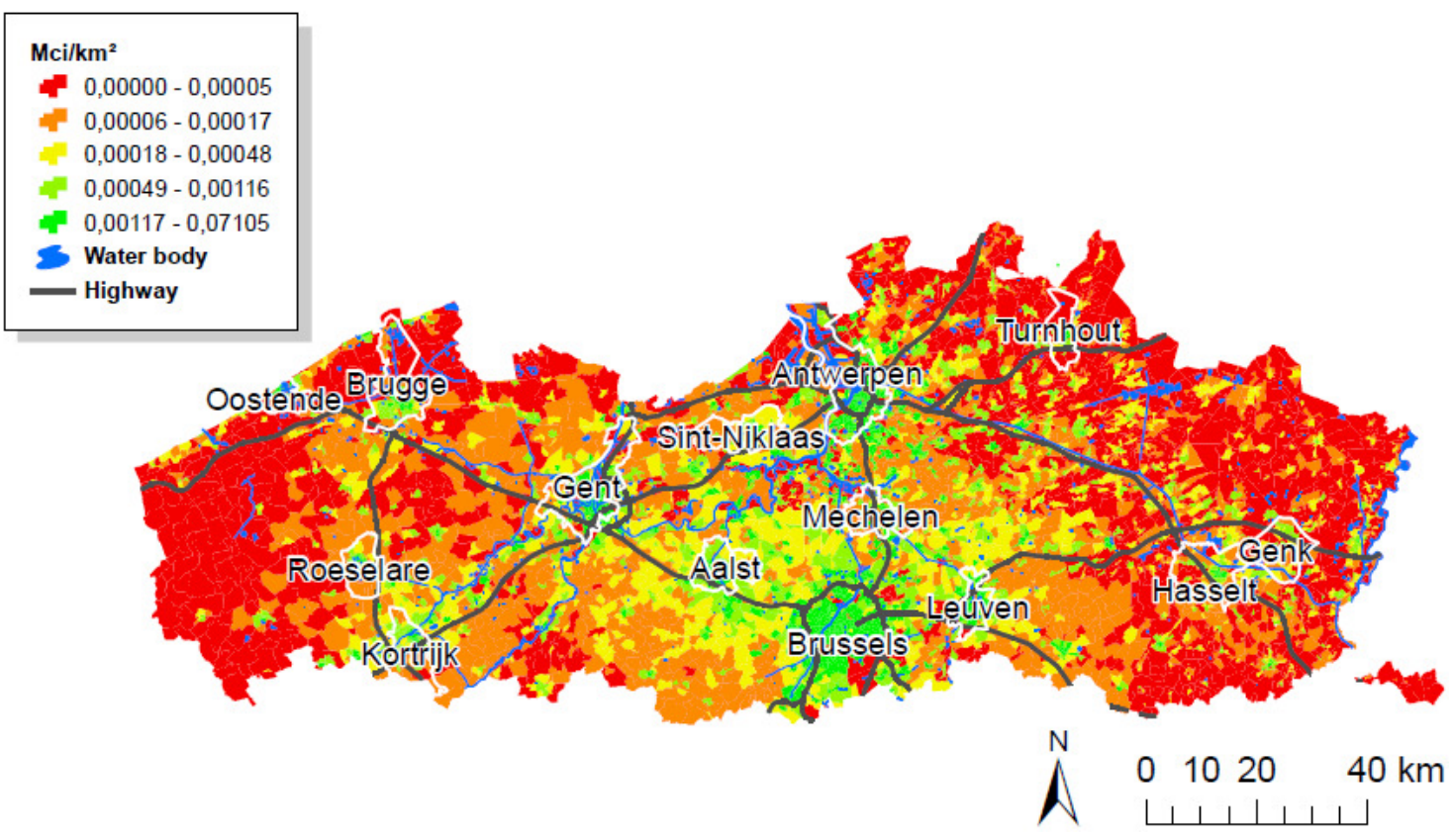

Figure 5. Social interaction potential of living in Flanders $\left(M_{c i}\right)$.

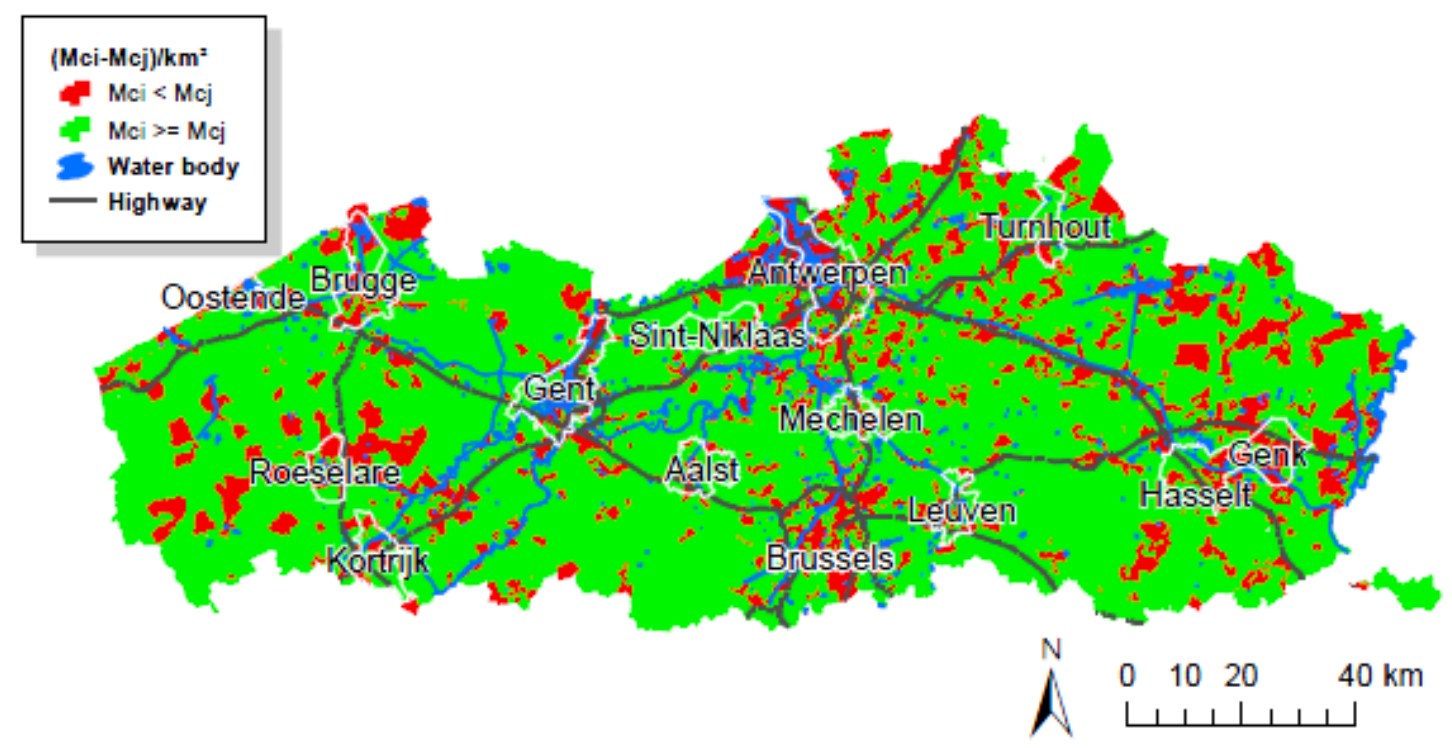

Figure 6. Difference in social interaction potential in Flanders between living and having a job $\left(M_{c i}-M_{c j}\right)$. 


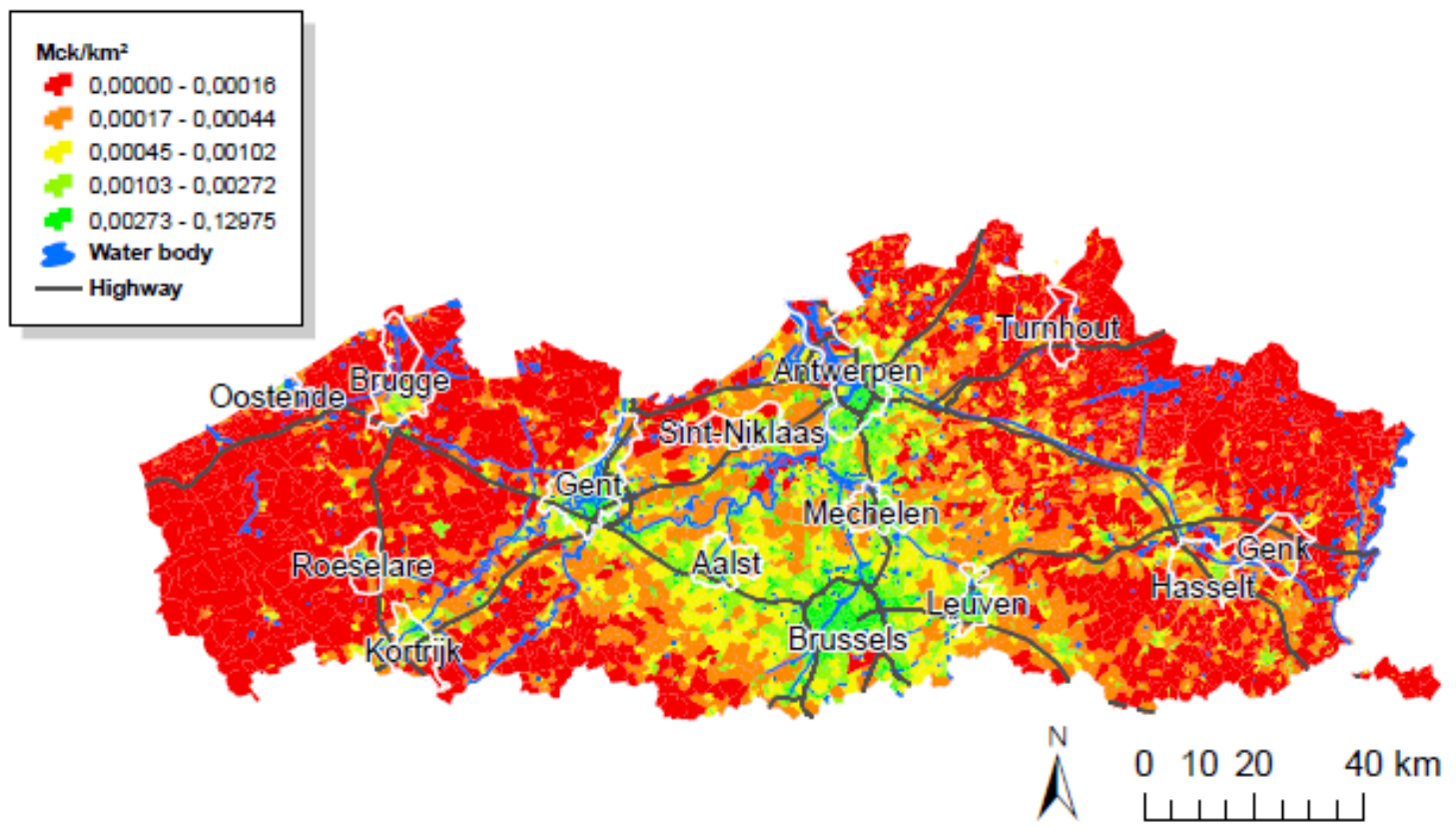

Figure 7. The amount of social interaction demand in Flanders $\left(M_{c k}\right)$. 


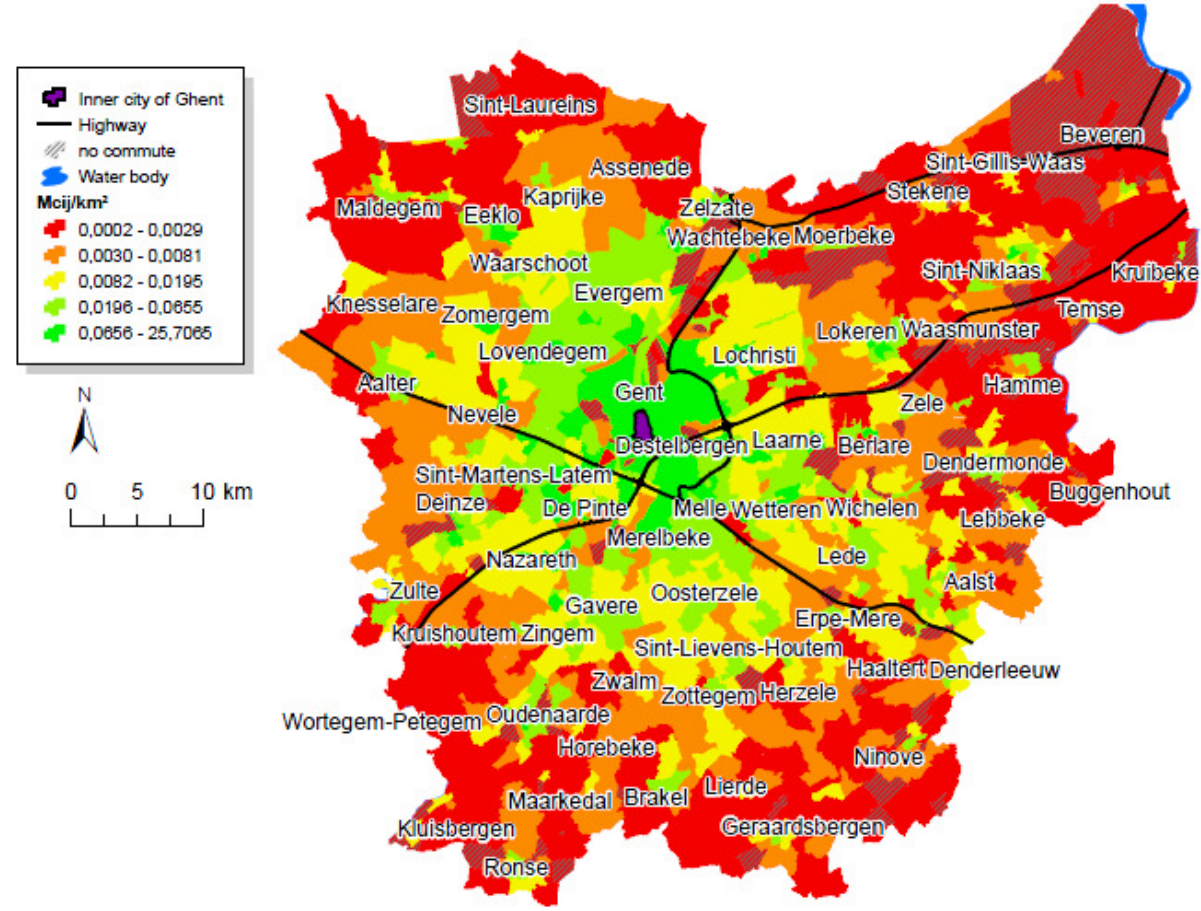

Figure 8. Social interaction potential per square $\mathrm{km}$ of living in East Flanders for people working in the inner city of Ghent $\left(\mathrm{M}_{\mathrm{cij}} / \mathrm{km}^{2}\right)$.

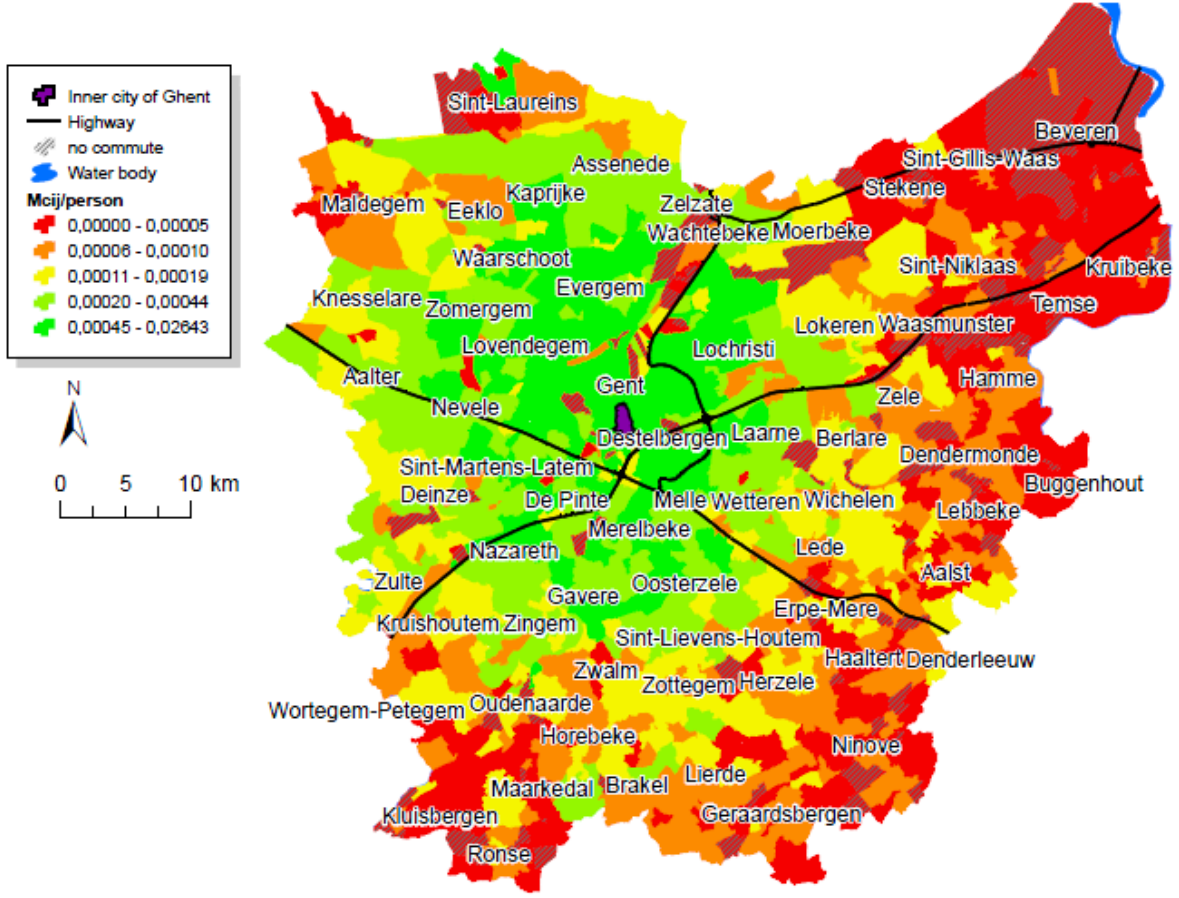

Figure 9. Social interaction potential per person of living in East Flanders for people working in the inner city of Ghent $\left(\mathrm{M}_{\mathrm{cij}} /\right.$ person). 
BRUSSELS

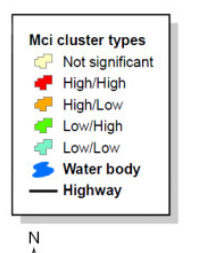

$\bigwedge^{N}$

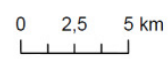

ANTWERP
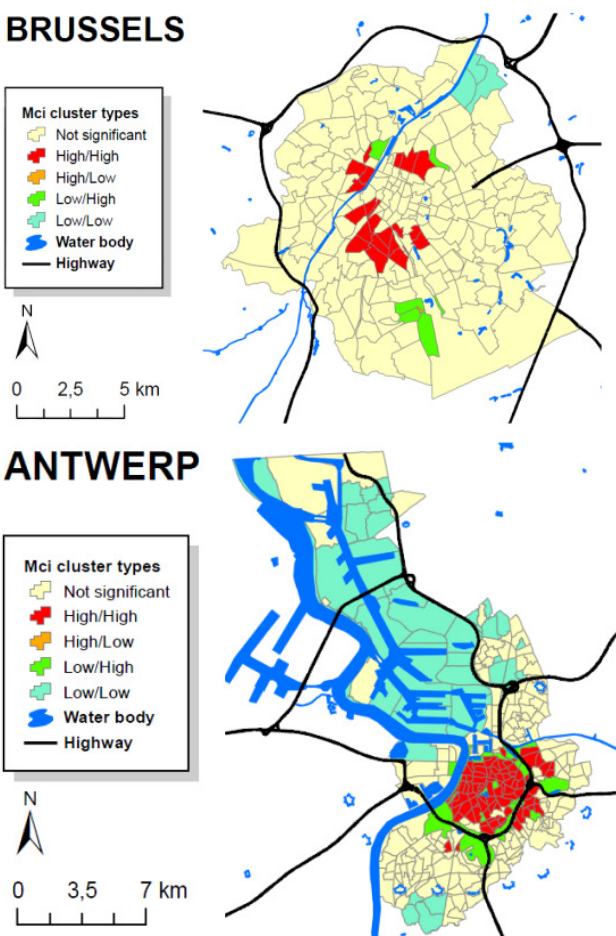

$\stackrel{0}{0 \quad 3,5,} 7 \mathrm{~km}$

GHENT

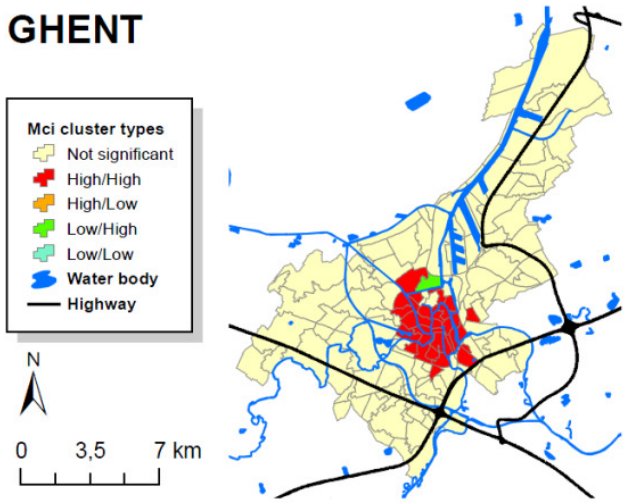

BRUGES
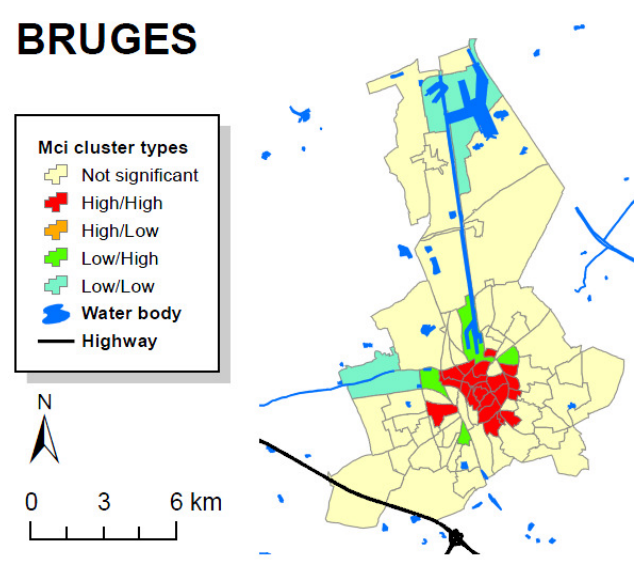

\section{LEUVEN}

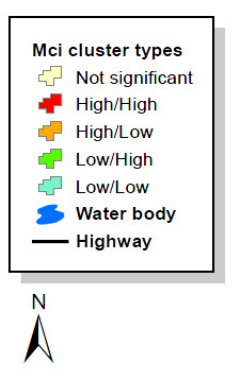

$0 \quad 24 \mathrm{~km}$

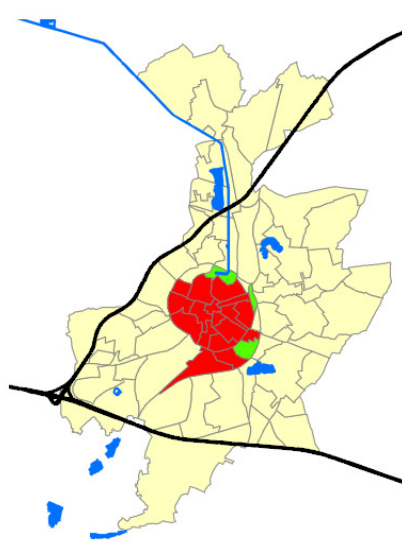

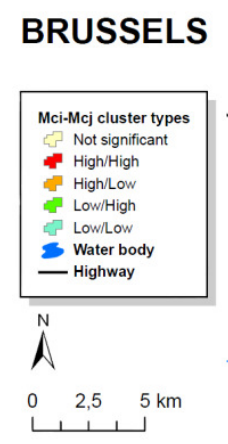

ANTWERP
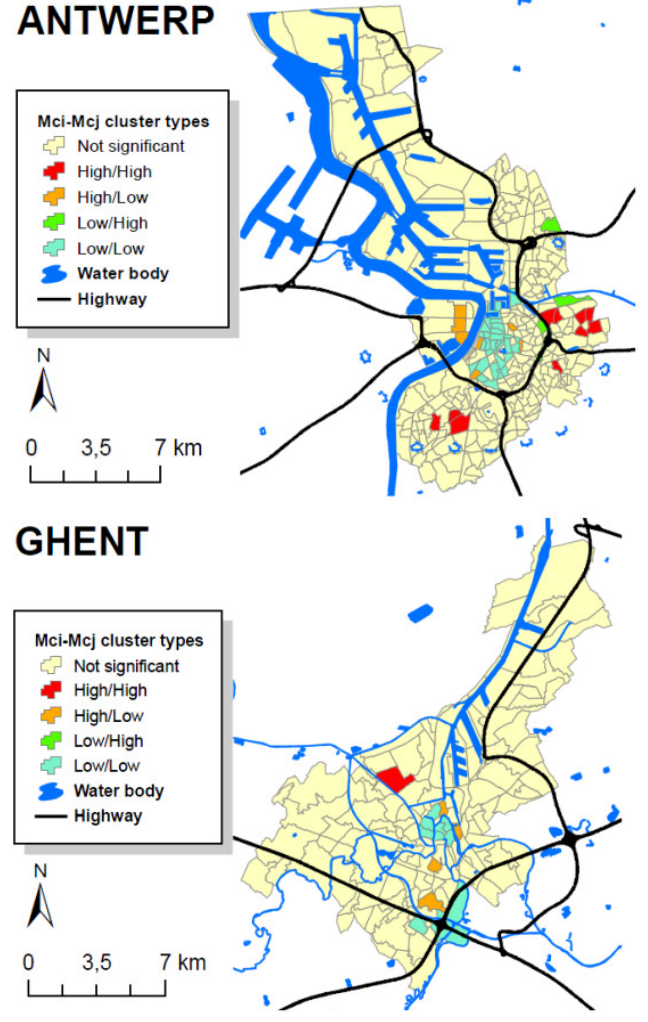

BRUGES
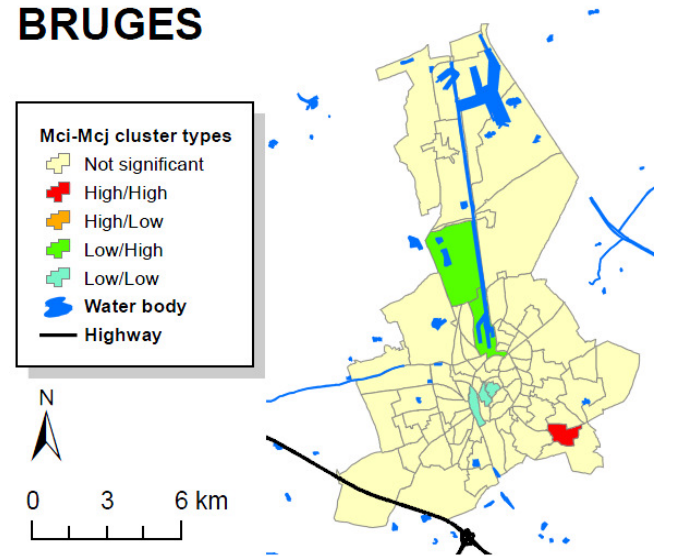

\section{LEUVEN}

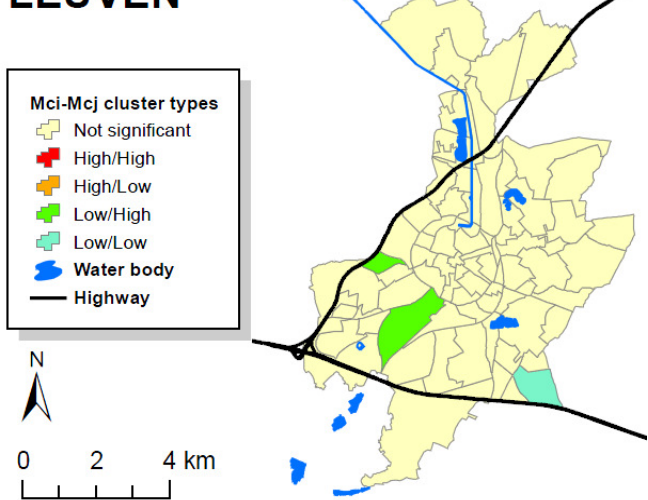

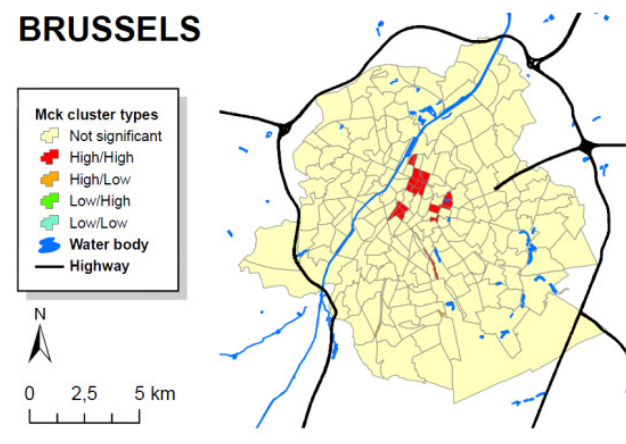

ANTWERP
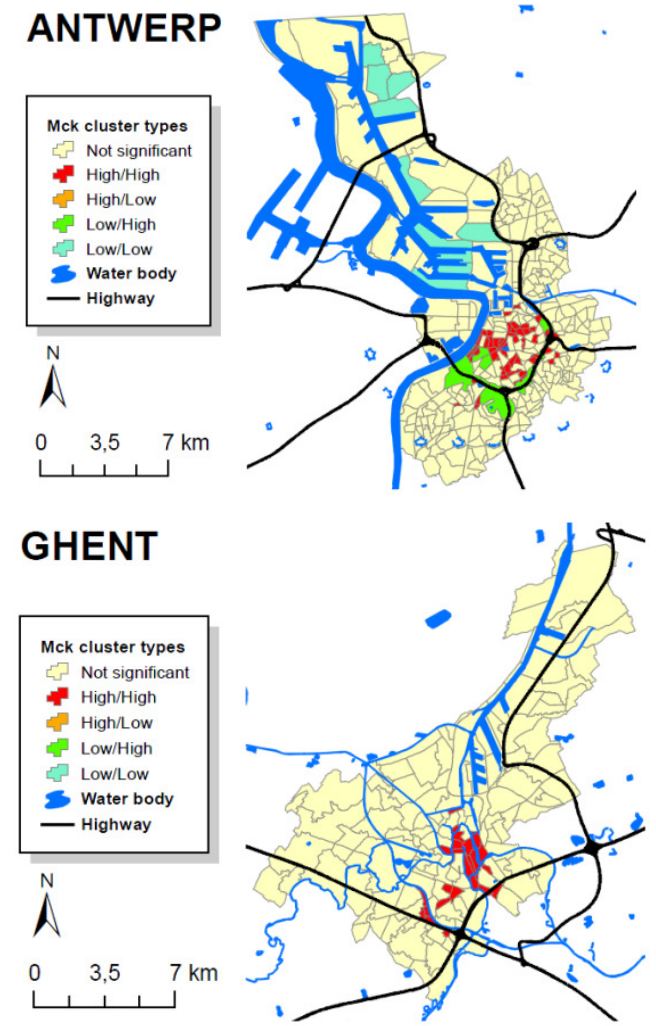

BRUGES

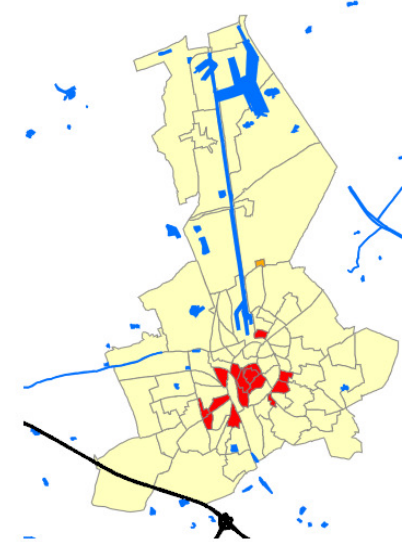

\section{LEUVEN}

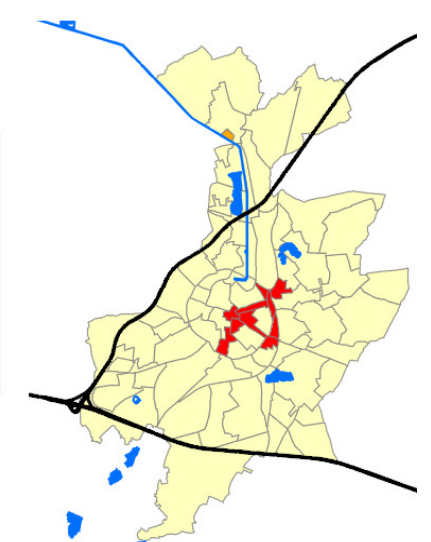

Figure 10. Clusters and outliers of social interaction potential of $M_{c i}$ (left), $M_{c i}-M_{c j}$ (middle) and $M_{c k}$ (right) in Brussels, Antwerp, Ghent, Bruges and Leuven. 


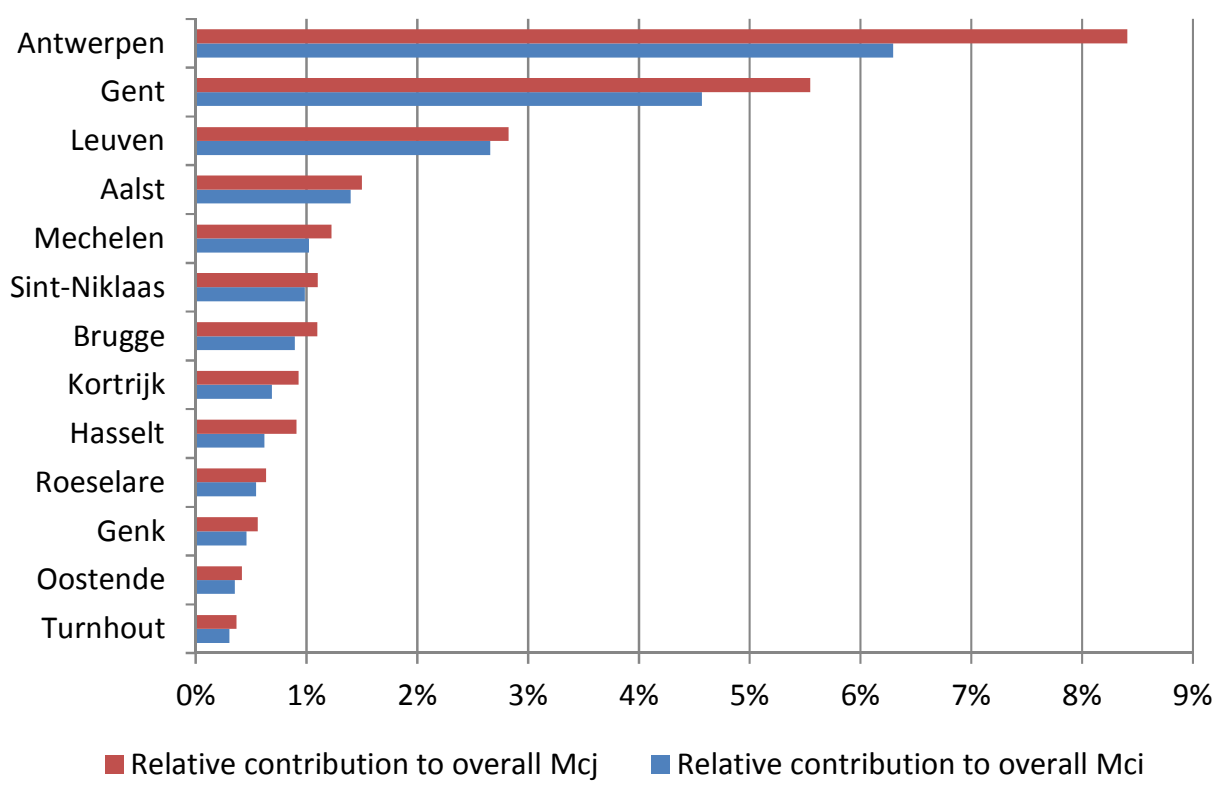

Figure 11. Contribution of the central cities to the overall social interaction potential of the studied region.

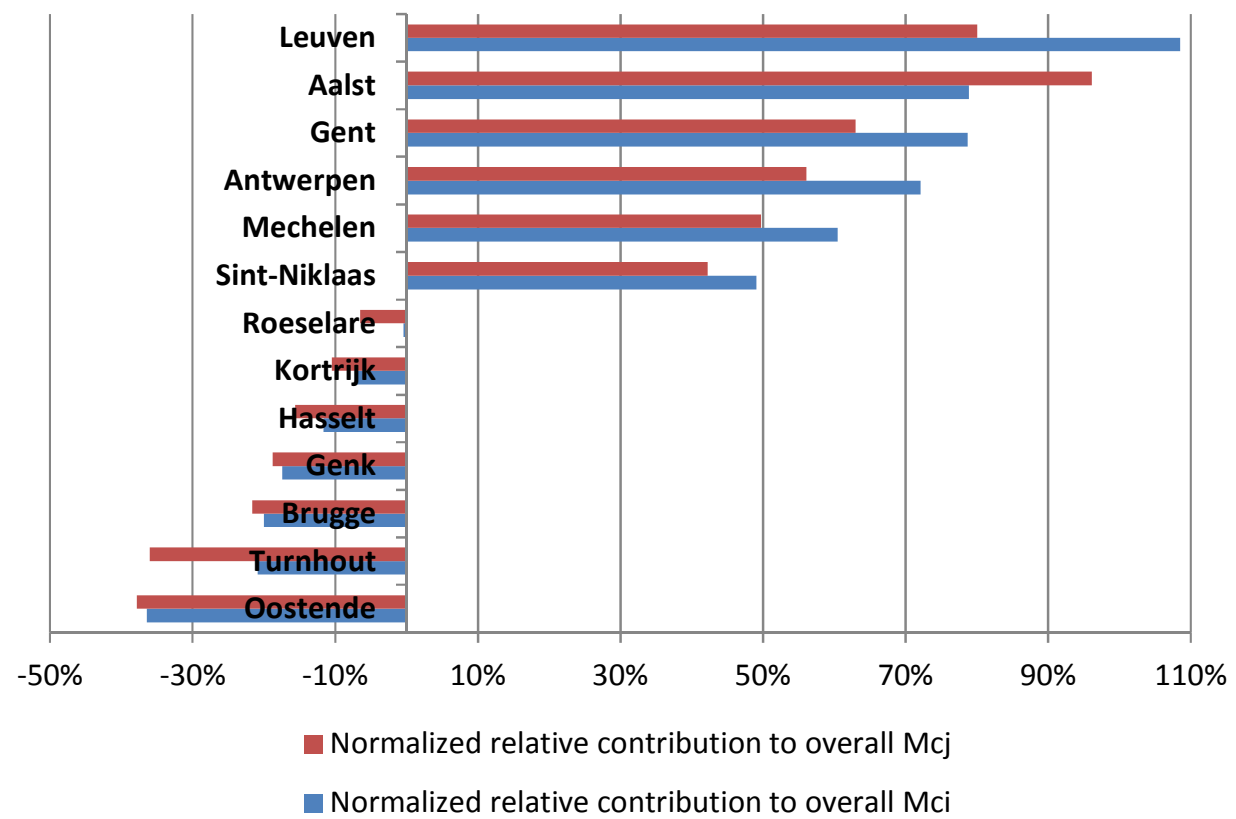

Figure 12. Contribution of central cities to the overall social interaction potential of the studied region relative to the contribution that is expected on the basis of their (residential and working) population shares within the region. 